Jocelyn Tillería

González y Fernando Vela Cossio

Jocelyn Tillería

González.

Arquitecta, Master en Conservación y Restauración del Patrimonio Arquitectónico.

Investigadora de la Escuela Técnica Superior de Arquitectura de la Universidad Politécnica de Madrid

Fernando Vela Cossio.

Doctor Arqueólogo. Profesor Titular del Departamento de Composición Arquitectónica de la Escuela Técnica Superior de Arquitectura de la Universidad Politécnica de Madrid.

\title{
Las viviendas de la colonización alemana en el sur de Chile
}

\section{Su influencia en la arquitectura tradicional. De Valdivia a Puerto Montt}

Palabras clave: vivienda tradicional, Chile, inmigración alemana, proyecto de colonización, arquitectura de madera, carpinteros de Chiloé, lago Llanquihue.

La ocupación efectiva del territorio austral chileno se produjo en la segunda mitad del siglo XIX. Para su ejecución fueron claves las medidas dictadas por el Estado a través del denominado "proyecto de colonización", que favoreció la llegada de inmigrantes procedentes de Europa durante un periodo de grandes flujos migratorios hacia el continente americano. La ciudad de Valdivia fue el punto de partida de este proyecto. En 1845 desembarcan los pobladores procedentes de los territorios de la Confederación Alemana. En esta ciudad se producen los primeros intercambios culturales entre la población local y la extranjera, en un "laboratorio constructivo" que estableció las bases de la arquitectura de la colonización y determinó la formación de la vivienda tradicional del sur del país. Mediante un estudio histórico y constructivo hemos identificado los invariantes arquitectónicos generados en este periodo de la colonización. Hemos comprobado su permanencia en distintos ejemplos de viviendas tradicionales localizadas, entre las ciudades de Valdivia y Puerto Montt, a lo largo del territorio que fue ocupado entre 1845 y 1875 con esta población alemana.

o que entendemos por arquitectura tra- dicional del sur de Chile es el resultado de un largo y complejo proceso de adaptación vernácula de las distintas tradiciones importadas de la construcción europea que se desarrollan desde mediados del siglo XVI hasta finales del XIX, entre el comienzo del extenso periodo colonial hispánico y la consolidación del Chile republicano. Para una mejor comprensión de este proceso de yuxtaposición de las diferentes arquitecturas de la tradición, adquiere gran importancia el análisis del denominado "proyecto de colonización", un amplio conjunto de políticas demográficas $\mathrm{y}$ económicas que propiciaron y vertebraron la ocupación del territorio austral con pobladores procedentes de Europa durante la segunda mitad del siglo XIX.

En este artículo trataremos de explicar la importancia de este proyecto de colonización en el proceso de formación de la arquitectura tradicional del sur del país, iniciado con inmigrantes procedentes de distintos territorios de la Confederación Alemana. ${ }^{1}$

La ciudad de Valdivia será el núcleo desde el cual se extenderán los tipos, sistemas, técnicas y materiales de construcción que darán forma a la arquitectura tradicional de esta región y se convertirá en un verdadero laboratorio arquitectónico para la configuración del Chile austral.

Hemos procurado aportar algunos antecedentes al estudio histórico-constructivo de estas arquitecturas tradicionales del sur chileno, principalmente en lo relacionado con su periodo de formación. Para ello, se han integrado con una mirada crítica las investigaciones existentes, tanto en el ámbito arquitectónico como en el más general histórico y social, eligiéndose la arquitectura de carácter residencial como el elemento vinculante. Para el estudio tipológico de estas primeras arquitecturas, y teniendo en cuenta la práctica inexistencia de planimetrías originales así como la escasa información documental escrita, hemos trabajado con el amplio registro fotográfico disponible. Formado por materiales de extraordinario interés, situados cronológicamente entre 1858 y 1900, ${ }^{2}$ de cuya consulta y análisis detenido se pueden extraer valiosas conclusiones para un mejor conocimiento constructivo y volumétrico de las edificaciones de todo el periodo.

Para el estudio de la influencia que tuvo la arquitectura realizada por los colonos alemanes en la formación de la arquitectura tradicional del sur de Chile, hemos querido ofrecer una mirada distinta a la de anteriores investigaciones. Así, se catalogaron los inmuebles edificados con posteridad a la propia etapa de la colonización alemana. Se trata de viviendas edificadas por constructores anónimos y no por colonos, que nos han permitido demostrar la permanencia de los invariantes arquitectónicos generados en el siglo XIX. Se han estudiado edificios residenciales en los territorios de la primera etapa de la colonización, entre Valdivia y Puerto Montt.

Los resultados de este trabajo forman parte de una investigación de mayor alcance sobre los orígenes y el desarrollo de la vivienda tradicional en Chile y su vincula- 
ción con los diferentes periodos de la inmigración europea. ${ }^{3}$

\section{El proyecto de colonización y la ocupa- ción del territorio austral}

Con la llegada del siglo XIX dará comienzo el complejo proceso de configuración de las incipientes repúblicas americanas. Chile reconoce en sus latitudes australes un extenso territorio deshabitado enormemente propicio para el desarrollo del sueño de la nueva república. El éxito extraordinario de la experiencia colonizadora en los Estados Unidos de América y los grandes flujos migratorios europeos de la segunda mitad del siglo XIX, impulsarán el desarrollo de un proyecto de colonización que persigue el crecimiento demográfico y económico que la nueva nación necesitaba: "en países como el nuestro, es de todo punto indispensable la activa cooperación del elemento extranjero; poderosa entidad que, al procurar enriquecerse, enriquece al país donde se asila" (Pérez Rosales 1886: 320).

Argentina, Brasil y Uruguay ya tenían en marcha proyectos de colonización, favorecidos principalmente por su conexión Atlántica con el viejo continente. Sin embargo, Chile será el primer país de la costa del Pacífico Sur que llevará a ejecución un proyecto de esta naturaleza. Las elites politicas e intelectuales chilenas de su tiempo fueron las principales impulsoras de esta iniciativa. Así, a las mencionadas ideas de desarrollo se unían las de globalización y desvinculación del pasado inmediato como colonia española.

Reconocido el valor del proyecto colonizador, el debate continuó a la hora de definir la procedencia de los inmigrantes europeos. En el texto del destacado político e historiador Benjamín Vicuña Mackenna titulado Bases del informe presentado al supremo gobierno sobre la inmigración extranjera, se registran las conclusiones de este debate y se cita que "el mejor colono posible es el alemán” (Vicuña 1865: 25), argumentando que, a diferencia de aquellos de otras procedencias, los germanos no abandonaban las tierras donde se trasladan, eran muy aptos para el desarrollo de labores de labranza y minas, y no representaban un riesgo para el país porque no formaban parte de una potencia maritima (como eran España, Francia e Inglaterra). No olvidemos que Chile es el país del Pacífico que cuenta con la más extensa línea costera del continente americano.

A la elección germana también contribuyó la procedencia de uno de los principales precursores de esta iniciativa, el marinero Bernhard Eunom Philippi que en 1842 descubrió el lago Llanquihue. Philippi difundirá los resultados de sus exploraciones en la Sociedad de Geografia de Berlín, suscitando en Alemania el interés por estas latitudes. En el año 1846 J.E. Wappäus publicaría la primera propaganda sobre Chile en Alemania, titulada Über die Vortheile welche das südliche Chile für deutsche Auswanderer bietet (Sobre las ventajas que el Chile austral ofrece a emigrantes alemanes) (Blancpain 1985: 44). Philippi tendrá un importante rol en la difusión de Chile como un territorio seguro, libre, y con potencial para el desarrollo económico de cualquier ciudadano alemán que quisieran avecindarse en el país. A partir de finales del siglo XIX, el proyecto de colonización admitirá emigrantes de
Figura 1. Ciudad de Puerto Montt en 1900. Fotógrafo: Odber Heffer. Fuente: Archivo Fotográfico, Museo Histórico Nacional de Chile, AF-79-19.

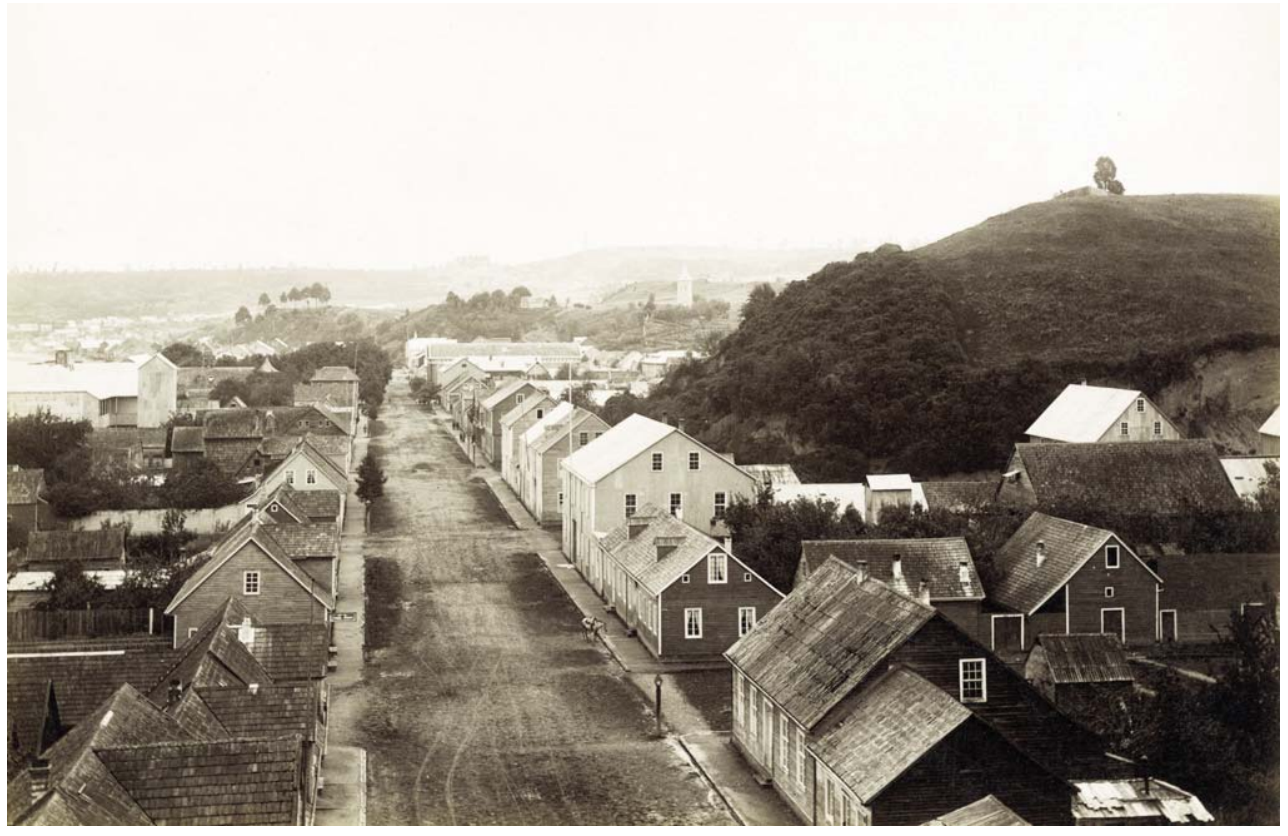


Figura 2. Paisajes de los territorios de la colonización, Lago Ranco (1934) y rio Pilmaiquen (1930). Fotógrafos: no identificados. En Museo Histórico y Antropológico Mauricio van de Maele y Archivo fotográfico Ellynor Fehrenberg del Centro Cultural Austral, Valdivia. (Alvarado y Matthews 2006: 112 y 115).

Figura 3. Mapa de localización de los territorios de la colonización y etapas de desarrollo. Fuente: Jocelyn Tilleria G. otras procedencias europeas, así como a la propia población nacional.

\section{El territorio de la colonización}

Durante los primeros años de la república el estado chileno contratará expediciones científicas con el objetivo de acopiar información demográfica y territorial actualizada del país e identificar fuentes para la explotación agropecuaria y minera. Son destacados los trabajos realizados por el francés Claudio Gay entre los años 1830 y 1837 (que permitieron documentar desde la región de Atacama por el norte hasta la isla de Chiloé, por el sur) así como las expediciones del polaco Ignacio Domeyko entre los años 1840 y 1846 (que entregó antecedentes del inexplorado territorio de la Araucanía). Estas expediciones pusieron en evidencia la existencia de grandes superficies de terreno libre y el abandono de los emplazamientos más australes del país: las ciudades de Valdivia, Osorno, Ancud y Castro.

La primera consecuencia de estos trabajos será la declaración como territorio de la colonización (1845) a todo el ámbito situado entre la ribera sur del río Biobío y el Cabo de Hornos, ${ }^{4}$ con una extensión estimada de $2.000 \mathrm{~km}$ de longitud, correspondiente a casi la mitad del territorio nacional y con condiciones agrestes en su extremo sur.

La inmigración oficial a Chile marcada por el proyecto de colonización, trascurre entre 1846 y los comienzos del siglo XX, fragmentada en dos etapas. La primera entre los años 1846 y 1875 , se desarrollará entre las ciudades de Valdivia y Puerto Montt con inmigrantes procedentes de la Confederación Alemana, además paralelamente se desarrollará la ocupación de la ciudad de Punta Arenas en el estrecho de Maga-
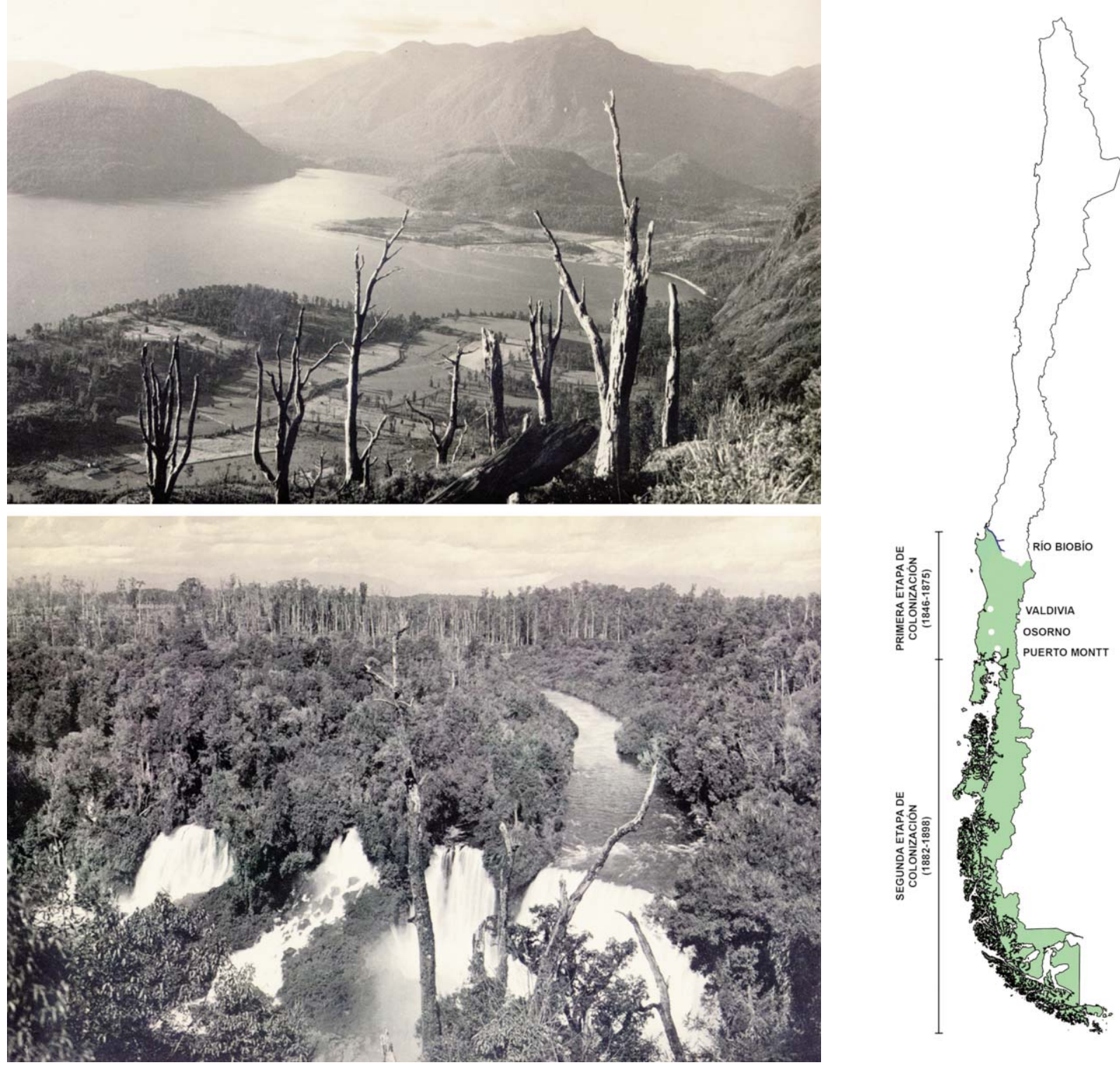
Figura 4. Cronología de la ocupación del territorio en la primera etapa de colonización. (Blancpain 1974: 70).

Figura 5. Valdivia en 1836. Lámina núm.6 (Gay 1854). llanes. ${ }^{5}$ La segunda etapa se inicia en el año 1882, con la formación de la "Agencia General de Colonización e Inmigración en Europa" con sede en París, que captará colonos procedentes de más de una decena de nacionalidades europeas, entre las principales se encuentran España, Francia e Italia. En el desarrollo de esta etapa los inmigrantes ocuparán los territorios de la Araucania, Chiloé, Aysén y Magallanes, hasta la isla Navarino. Finalizada la inmigración oficial en 1898, continúa la inmigración libre que transcurrirá hasta la crisis de los años 30.
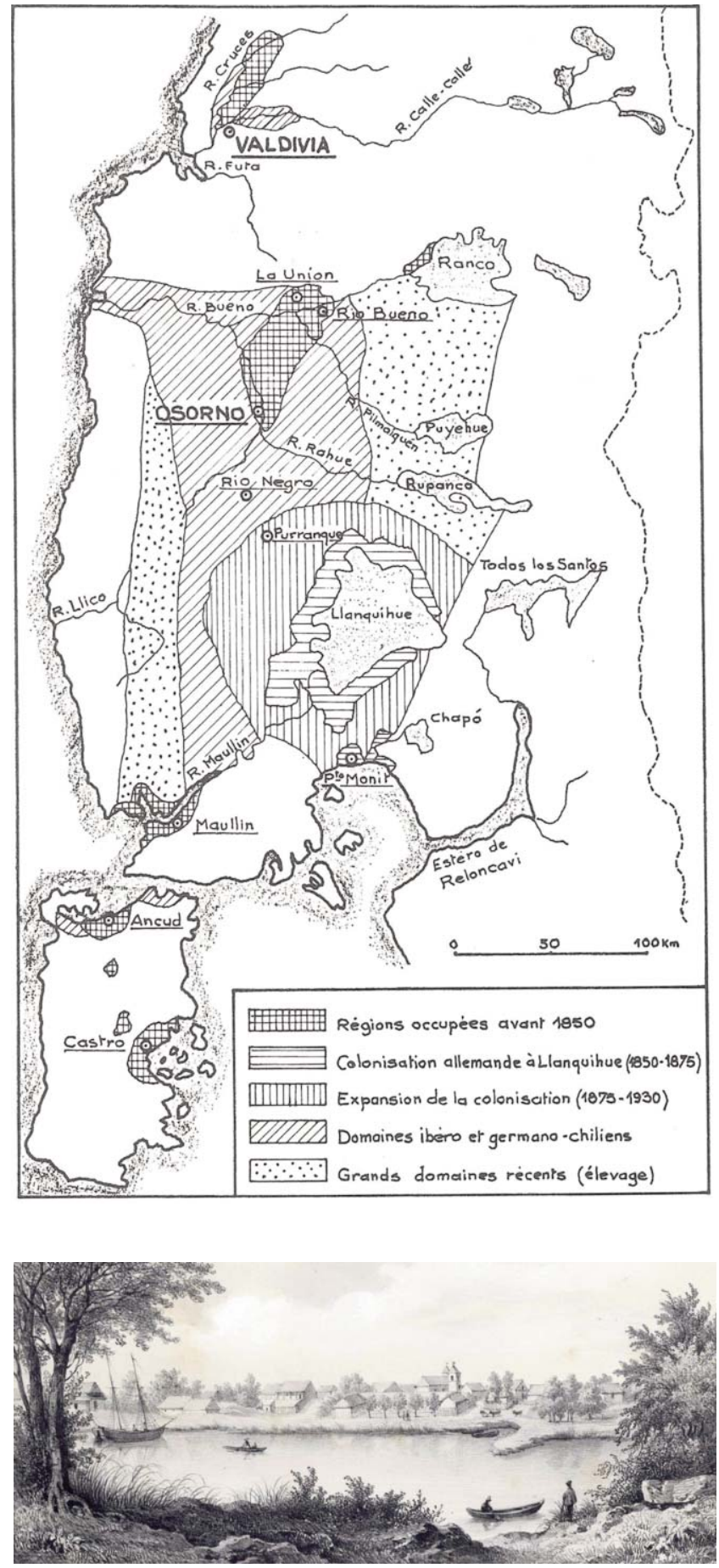

Durante la primera etapa de colonización, la república de Chile puso a disposición un territorio con una superficie aproximada de $21.000 \mathrm{~km}^{2}$, formada por bosques densamente poblados, lagos, ríos caudalosos, pequeños núcleos de urbanos (Valdivia y Osorno), y una población indígena dispersa. Un territorio caracterizado por su fertilidad, el "que de todas las provincias de Chile más se asemeja al temperamento de la parte septentrional de Europa" (Domeyko 1846: 98).

\section{Valdivia: laboratorio constructivo de la colonización}

Entre los años 1846 y 1850 desembarcan en el muelle de Corral, situado en las proximidades de Valdivia, los primeros colonos procedentes de las regiones centroeuropeas de Hesse, Wurtemberg, Silesia, Westfalia, Bohemia y Brandeburgo, ${ }^{6}$ la situación política de la confederación alemana contribuyó a que la emigración alemana fuera muy alta en América durante la primera mitad del siglo XIX, siendo Estados Unidos uno de los principales destinos.

La ley del 18 de noviembre de 1845 dio el marco legal a la colonización oficial, estableció los derechos y obligaciones de los colonos otorgando un respaldo político a los participantes de esta empresa. Los interesados debian ser padres de familia y no haber tenido condena por crimen o simple delito. Por su parte el estado de Chile se comprometía a otorgarles la nacionalidad, la entrega de un terreno en función del tamaño de la familia, herramientas y semillas para el cultivo, el respaldo financiero durante un año a través del pago de un salario, y el traslado desde el puerto de llegada al lugar de destino, gastos que debían ser mas tarde devueltos por los colonos al estado. Un importante beneficio fue la exención del pago de impuestos durante veinte años. Complementaria a esta ley orgánica se establecieron otras adaptadas a las necesidades de cada colonia.

Antes de la colonización, Valdivia ya contaba con casi tres centurias de existencia, sin obtener grandes avances urbanos y arquitectónicos, presentaba un aspecto de emplazamiento provisional con calles sin pavimentar y sin construcciones de relevancia, el desarrollo urbano y constructivo se había visto truncado por periodos de abandono, incendios y terremotos. ${ }^{7}$

En el año 1846 se contabilizan 259 casas, datos entregados por el intendente de la provincia Salvador Sanfuentes (Greve 1940: 46). En relación a sus construccio- 
Figura 6. Viviendas de Valdivia en 1835. Se reconocen los muros de postería (Darwin, Fitzroy y King 1839: 398-399).

Figura 7. Dibujo de Rodulfo Amando Philippi en 1853 de las viviendas de Valdivia. Destacan los corredores exteriores y grandes cubiertas con claraboyas (Guarda 1995: 21).

Figura 8. Costanera de Valdivia en 1870 Fotógrafo: Christian Enrique Valck (Alvara do y Matthews 2005: 36).

Figura 9. Volumen pri mario en plaza de Val divia año 1858. Fotógrafo: Christian Enrique Valck (Alvarado y Matthews 2005: 38).

Página siguiente. Figura 10. Construcciones de Valdivia. Fotografia datada entre 1858 y 1860. En primer plano edificación de origen colonial hispano y al final de la calle, volumen primario con mirador. Fotógrafo: Christian Enrique Valck (Alvarado y Matthews 2005: 48). nes, los registros documentales de Vicente Pérez Rosales, ${ }^{8}$ Rodulfo A. Philippi ${ }^{9}$ y los registros gráficos del capitán Phillip Parker King que comandaba la expedición de que era parte Charles Drawin, 10 refieren a viviendas de un nivel con muros de troncos de madera dispuestos en vertical, sin cimentación, enterrados en la tierra, sistema constructivo denominado de postería (Guarda 1980 y 1995). Grandes cubiertas de madera armadas de par y nudillo, revestidas de tablas de alerce o de tejuela, y con corredor exterior. Existen registros de edificaciones realizadas con mampostería de piedra y albañilería de barro cocido, sistemas constructivos no expandidos. La composición de fachada era muy elemental, puerta central y pequeños huecos para las ventanas. En el interior pavimento de tablones de madera y unas pocas habitaciones entre las que destaca la permanencia del estrado.

El nivel de conocimiento de técnicas constructivas en madera eran mínimas, a pesar de la abundancia de este material, la existencia de sierras hidráulicas para la comercialización de tablas, y la presencia de astilleros para la fabricación de embarcaciones (Guarda 1980). Se trabaja principalmente con hacha y "no había carpinteros a no ser acaso algún desertor de buque, así es que el cepillo y otros instrumentos de carpintería eran casi desconocidos" (Philippi 1901: 300).

Los primeros colonos se instalaron en las proximidades de la propia ciudad de Valdivia: isla Teja, Arique, Cutipai, Niebla, Amargos y San Carlos (Blancpain 1974), en terrenos donados por vecinos al no existir terrenos fiscales disponibles.

Las profesiones y oficios declarados por los recién llegados colonos fueron muy diversas. Si tomamos como ejemplo los pasajeros de la embarcación "Hermann" que desembarca en 1850, la mayoría eran comerciantes, farmacéuticos, y de otros oficios relacionados con la agricultura y la ganadería, y en menor proporción artesanos relacionadas con la construcción. Las investigaciones registran que los colonos acaudalados se establecieron en la ciudad de Valdivia dispuestos a establecer comercios e industrias, los restantes se situaron en el territorio rural.

A casi quince años de la llegada de los primeros colonos alemanes a Valdivia, ya era perceptible su influencia en la arquitectura y la ciudad. A partir de los registros gráficos y documentales realizados entre los años 1846 y 1860 hemos reconstruido las características de estas nuevas construcciones. Nos centraremos en el estudio de las viviendas por corresponder a la tipologia arquitectónica más extendida, y porque su capacidad documental nos permite conocer la esencia de la sociedad, desde una perspectiva arquitectónica y social.

Con relación a su situación urbana, las nuevas construcciones conservaron las formas de emplazamiento existentes en la ciudad. Se situaron en un extremo del solar, con fachada principal a pie de calle, y en el interior del solar huertas y jardín. Las nuevas edificaciones se arman con un volumen compacto, sin corredor, con planta rectangular de un nivel, amplia cubier-
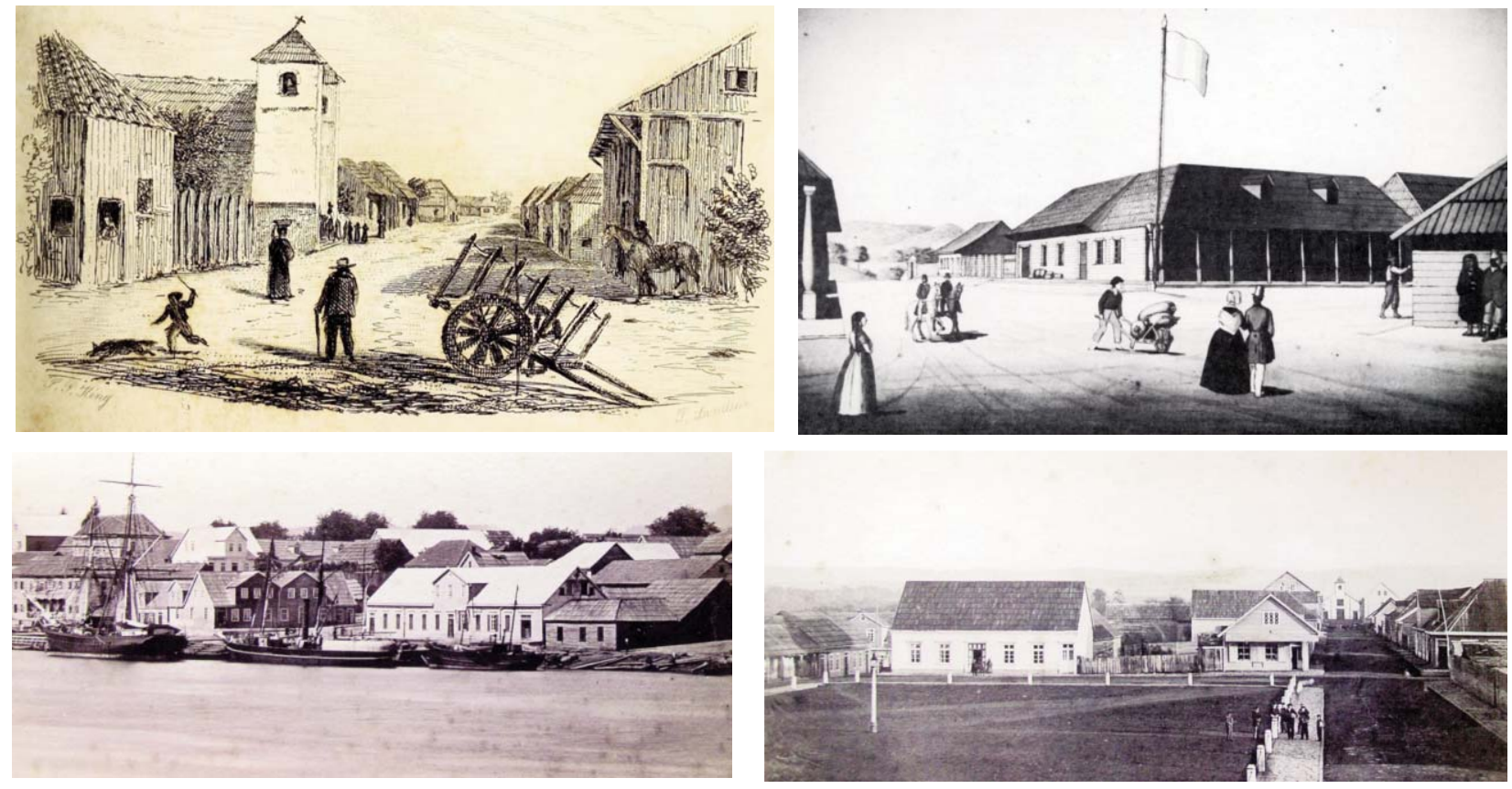
Figura 11. Esquemas tipológicos de viviendas. Volumen primario $y$ volumen primario con mirador (Jocelyn Tilleria G.).

Figura 12. Plano de vivienda con mirador, año 1850. Autor: Wilhelm Frick, en Archivo Nacional de Chile (Guarda, 1995: 22).

Figura 13. Esquema de plantas de viviendas de colonos alemanes de las ciudades de Osorno, Puerto Octay y Valdivia, basado en los datos publicados por Guarda y Montecinos entre los años 1980 y 1981 (Jocelyn Tilleria G.).
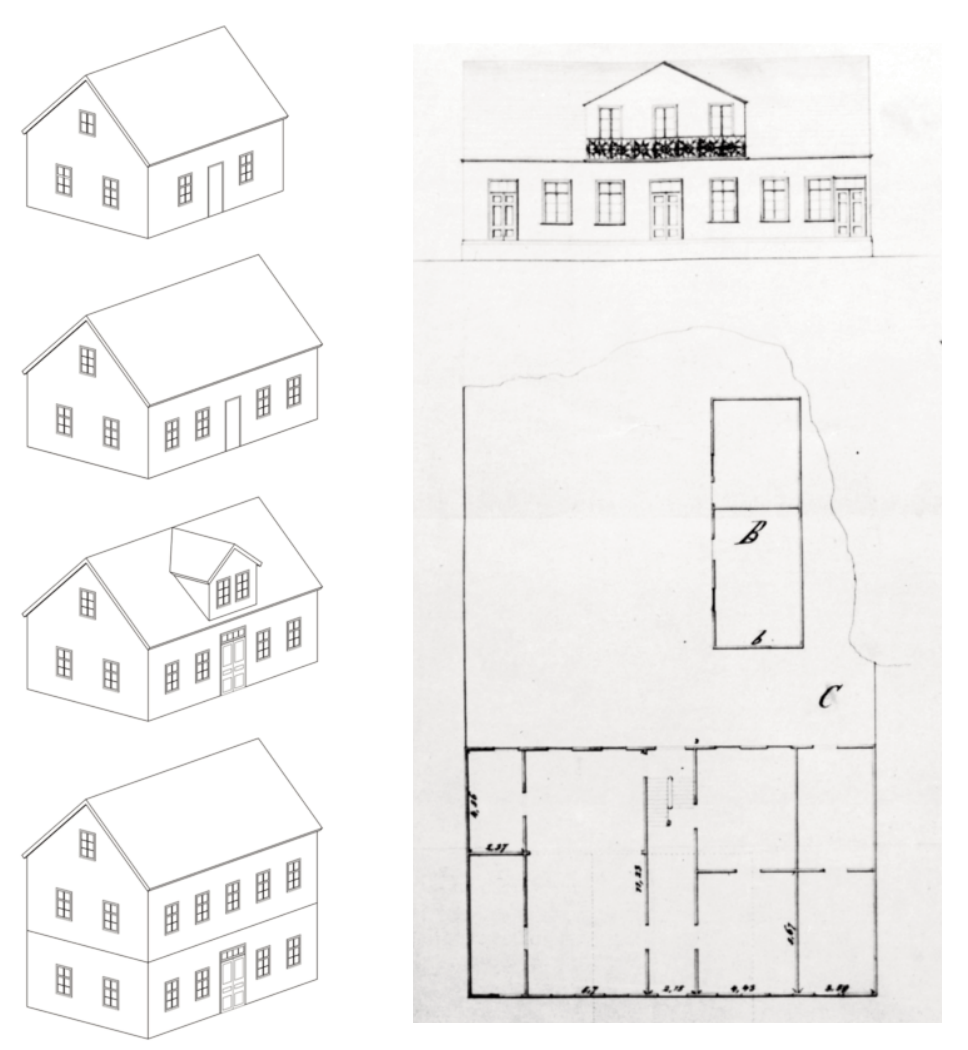

ta a dos aguas con una altura igual o mayor que el primer nivel, en una relación de $1 / 2$ a $3 / 5$ de la altura total del inmueble, y entre un $80 \%$ y $90 \%$ de pendiente. Una geometría elemental que hemos denominado "volumen primario".

Entre las variables con que puede contar este volumen se encuentra la incorporación de un cuerpo perpendicular a la cubierta denominado mirador, que permite hacer habitable el espacio bajo cubierta, herencia de la estructura denominada zwerchhaus ${ }^{11}$ con origen en la Edad Media
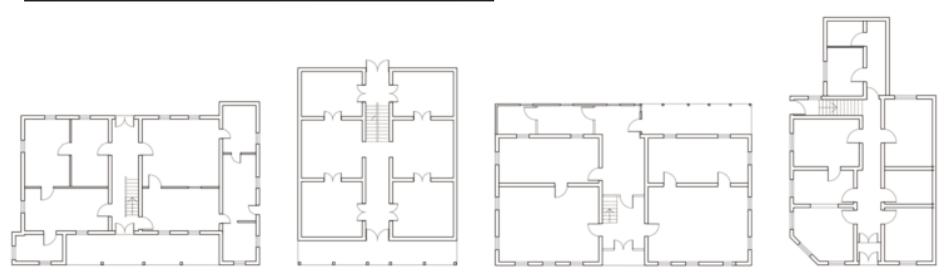

que es utilizada "para dar acceso a la buhardilla o como espacio de almacenamiento prolongado" (D'Alençon y Prado 2013: 38). A las edificaciones que incorporan este elemento las hemos denominado "volumen primario con mirador".

El espacio bajo cubierta siempre fue utilizado en Valdivia para almacenaje, por ello las cubiertas ya incorporaban claraboyas, 12 tal como registra el dibujo de Rodulfo Amando Philippi realizado en 1853. El "mirador" se consolidará como el elemento característico de esta nueva arquitectura. Los arquitectos Guarda y Cherubini coinciden en que Wilhelm Frick ${ }^{13}$ fue el primero en integrar este elemento en Chile, ya sea por su obra de la Aduana de Corral en 1854 o por un plano de su autoría realizado en 1850.

Surge además una nueva configuración espacial dada por un nuevo diseño de planta de vivienda, consistente en "un pasillo central, a través del cual se accede a todas las habitaciones, separando de una manera sencilla las diferentes actividades que se desarrollan al interior de la vivienda como recibir visitas, cocinar comer y dormir. En este pasillo se coloca una escalera que llega al entretecho o soberado, ${ }^{14}$ que de esta manera se vuelve habitable" (Cherubini 2016: 47). Esta planta también se registra en el plano de Frick antes citado, su diseño será replicado en toda la colonia.

Una de las principales contribuciones realizadas por los colonos a la arquitectura de Valdivia, fue la importación del sistema constructivo de entramado de madera derivado del fachwerk, en una versión más simplificada donde se redujeron el número de piezas y se eliminaron las uniones más complejas. Además, los gefach (espacios entre entramados de muro) no se encuentran rellenos como en el fachwerk; la estructura se reviste en su cara exterior con tinglado (tablas de madera dispuesta en horizontal solapadas) o tejuela, y por el interior revestimiento de tablas.

Otra de las innovaciones traídas por los colonos alemanes es la nueva composición de fachadas, en las que se incorporan más vanos y de mayor tamaño. Los interiores se vuelven más luminosos. Sobre el dintel de las puertas de acceso se dispone una ventana que cubre todo el ancho del vano y que permite iluminar el pasillo central. Se construyen "galerias vidriadas en reemplazo de los corredores porticados exteriores" (Cherubini 2016:49), generando un nuevo espacio iluminado para los dias nublados. Los tamaños de puertas y ven- 
Figura 14. Plano de parcelación del lago Llanquihue realizada por Decher y Hess entre 1853 y 1875.

Dibujo de Jean Pierre Blancpain. Anexo planimétrico (Blancpain 1970).

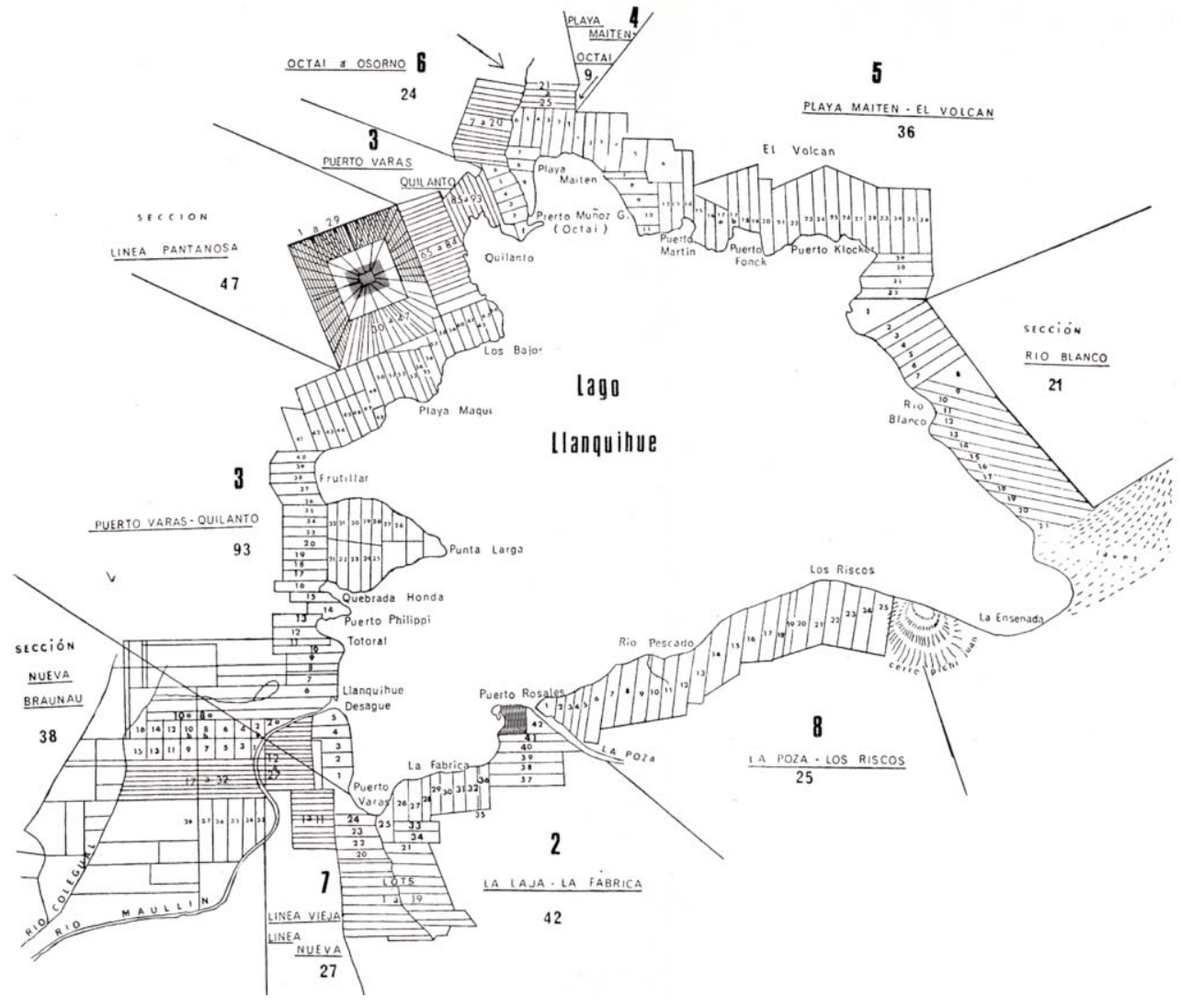

tanas se estandarizan al ser fabricados por talleres de carpintería especializados (Cherubini 2016). En la composición de fachadas se reconoce la simetría y alineación de vanos. En la cubierta se continúa utilizando la tejuela como principal revestimiento, y a partir de 1860 y 1870 se incorporarán las planchas de hierro galvanizado, extendido su uso como revestimiento de muros. El éxito de este material es la protección que otorga a las estructuras de madera, reduciendo los trabajos de mantenimiento y a su impermeabilidad en una de las ciudades más lluviosas de Chile. El diseño de planchas más utilizado corresponde a las onduladas, y a partir del siglo XX se incorporarán nuevos que imitan a la albañilería y a la sillería almohadillada.

No hemos encontrado antecedentes que hagan alusión a los talleres de carpintería instalados por los colonos, pero las edificaciones antes descritas confirman la existencia de mano de obra especializada que llega a la ciudad, de igual modo que en los registros administrativos de profesiones declaradas. Estos talleres no solo debieron realizar el armado de puertas y ventanas, sino también de mobiliario, tomando en consideración a las demandas de los nuevos habitantes. Postulamos que debieron existir transferencias constructivas entre la población local y los colonos, ya que se continúan utilizando los revestimientos de tejuela y tinglado utilizados antes de la presencia germana, así como el uso de las especies madereras autóctonas. Además, los colonos debieron contratar trabajadores nacionales, lo que permitió la transmisión de nuevas técnicas y aunque el número de carpinteros germanos fuera escaso, hemos encontrado registros de que muchos de los colonos antes de embarcarse en esta empresa aprendieron técnicas de carpintería y herrería, oficios que les serian útiles en el nuevo mundo (Blancpain 1970, Peri 1989), contribuyendo también a la expansión de las nuevas técnicas.

Los cambios experimentados en la ciudad de Valdivia, la transformación del paisaje y el florecer de una nueva estética urbana, demostraron la rápida adaptación de los colonos a este nuevo escenario, así como la pronta asimilación de las nuevas maneras de habitar por parte de la población local. Consideramos Valdivia como el laboratorio constructivo del proyecto de colonización austral de Chile, y creemos que en ella se sentaron las bases de las formas de habitar que se expandirán por todos los territorios de la colonización.

\section{Las viviendas de la colonización del lago Llanquihue}

La ocupación de este territorio supuso un proyecto diferente al realizado en Valdivia, 
producto de las condiciones geográficas, la falta de vias de comunicación, el impenetrable bosque y la falta de núcleos urbanos.

El estado chileno encarga a los agrimensores alemanes Ferdinand Hess y Juan Decher los trabajos de trazado y parcelación de esta colonia entre los años 1853 y 1875 , periodo en el cual se dividieron más de 35.000 hectáreas en un total de 340 hijuelas (Blancpain 1985: 94). Las parcelas resultantes fueron de planta cuadrangular alargada, dispuestas de forma perpendicular al lago, con extensiones de 50 a 100 cuadras, 15 distribuidas en función del tamaño de la familia que iba a residir. La estrechez de los terrenos permitió generar proximidades entre las propiedades facilitando la comunicación entre los miembros de la colonia (Blancpain 1970: 24).

Reconocemos en la elección del tipo de parcelación la influencia de la experiencia colonizadora alemana de los siglos XI y XII a través de las denominadas Waldhufendorf, utilizadas para la ocupación de territorios de montaña y bosque. Este sistema de colonización se inicia con el trazado de propiedades alargadas, dispuestas perpendicularmente a una vía de comunicación que puede ser un camino o un río (Gutkind 1964). La ocupación de la parcela se inicia con la edificación de una vivienda en el extremo del terreno próximo a la vía de comunicación; a partir de ella se procede al desbroce para ganar terreno al bosque. En la colonia de Llanquihue el eje de comunicación fue el borde lacustre que se consolidó como la principal vía de comunicación, debido a su capacidad de navegable.

La ocupación del lago se inicia en 1856 por sus extremos norte y sur. El sector deno- minado "Playa Maitén" por el norte, fue poblado en su mayoría por colonos procedentes de las provincias de Silesia, Brandenburgo, Westfalia y Turingia. Y por el sur, en las áreas denominadas "La Fábrica" y el "Desagüe", por emigrantes de las regiones de Hesse, Sajonia, Silesia y Suabia (Blancpain 1974). Las ocupaciones declaradas fueron artesanos y campesinos, generando una economía principalmente vinculada a la producción agropecuaria.

En 1856 ya habitaban en la ribera del lago 110 familias de colonos, en 1861250 familias y en 1864262 familias, con una población estimada de 1.491 extranjeros (Blancpain 1970: 13).

La estrategia de ocupación territorial de este lago no incorporó en sus inicios la fundación de ciudades, de forma espontánea se fueron concentrando los servicios en las proximidades de los primeros emplazamientos ocupados. Así se crearon los núcleos urbanos de Puerto Octay, ${ }^{16}$ Puerto Varas ${ }^{17}$ y Llanquihue. ${ }^{18}$ Un caso distinto fue el de la ciudad de Frutillar, único emplazamiento del lago fundado en el primer periodo de la colonización en 1856. Por otra parte, la ciudad de Puerto Montt fundada en 1853, a pesar de no formar parte de la ribera del lago se vincula a su colonización al consolidarse como su principal puerto marítimo, una situación que trataremos más adelante.

Para la obtención del título de propiedad el estado exigía la edificación de una vivienda y el cultivo de dos cuadras de terreno en el plazo de un año. ${ }^{19}$ Para su ejecución se les entregaban "semillas hasta por valor de cinco pesos, una yunta de bueyes, una vaca parida, quinientas tablas i un quintal de clavos" (Vicuña 1865: 113), además de
Figura 15. Vista de Puerto Octay en la segunda mitad del siglo XIX. Fotógrafo: no identificado. Fuente: Archivo Fotográfico, Museo Histórico Nacional de Chile, AF126-11.

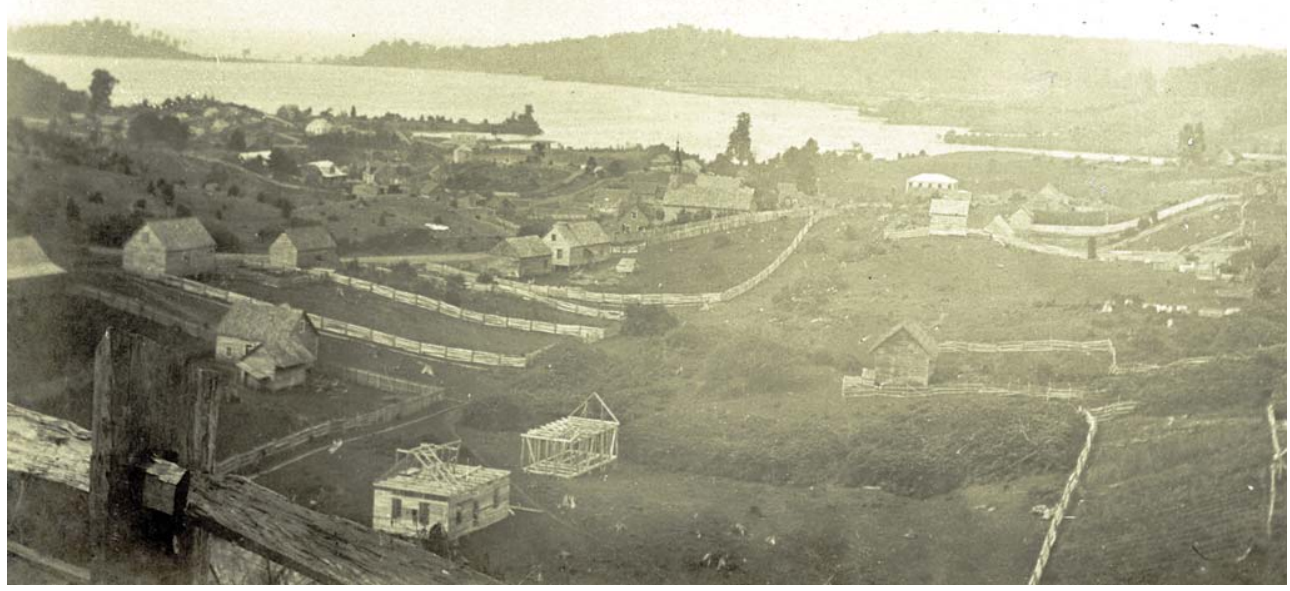


Figura 16. Formas de agrupación de edificaciones en granjas de la colonia alemana del lago Llanquihue. Dibujo de Johanna Moser. (D'Alençon y Prado 2013: 127). una asignación mensual en dinero que debía ser cobrada en la ciudad de Puerto Montt.

La ocupación del terreno se iniciaría con la construcción de un refugio y el despeje del terreno. Una descripción de 1856 registra: "nuestra primera casa habitación fue una rancha techada con tejuelas y ramas en medio de la selva" (Peri 1989: 72). Las tareas de desbroce fueron realizadas a hacha y fuego.

A casi diez años de entregados los primeros terrenos ya era posible reconocer el avance que había alcanzado la colonia. Uno de los chilenos precursores de este proyecto registra:

"se ven a cada cinco cuadras dos bonitas casas, una frente a la otra, en uno y otro lado del camino. Cinco cuadras es el frente de cada propiedad rural, y cada una constituye con sus edificios habitables, sus graneros, sus establos, jardines, arboledas, potreros y sembrados, máquinas agrícolas, conservatorios y talleres de algu- na industria especial". (Pérez Rosales 1886: 372)

El borde del lago se fue poblando con pequeñas granjas que eran trabajadas por sus propietarios. Se armaban por un conjunto de edificaciones agrupadas en torno a un espacio central. Las investigaciones de D'Alençon y Prado reconocen como una de las principales diferencias con las granjas alemanas la falta de edificaciones con programas mixtos, las denominadas Einfirsthof, granjas de una sola cumbrera que agrupan actividades residenciales y productivas (D'Alençon y Prado 2013: 126).

También hemos podido comprobar que las viviendas edificadas en los primeros cuarenta años de la colonia de Llanquihue fueron de similares características a las realizadas en la ciudad de Valdivia, lo que demuestra la formación y expansión de tipos arquitectónicos en la colonia germana en Chile.

Predominaron las de tipo "volumen primario" y "volumen primario con mirador",
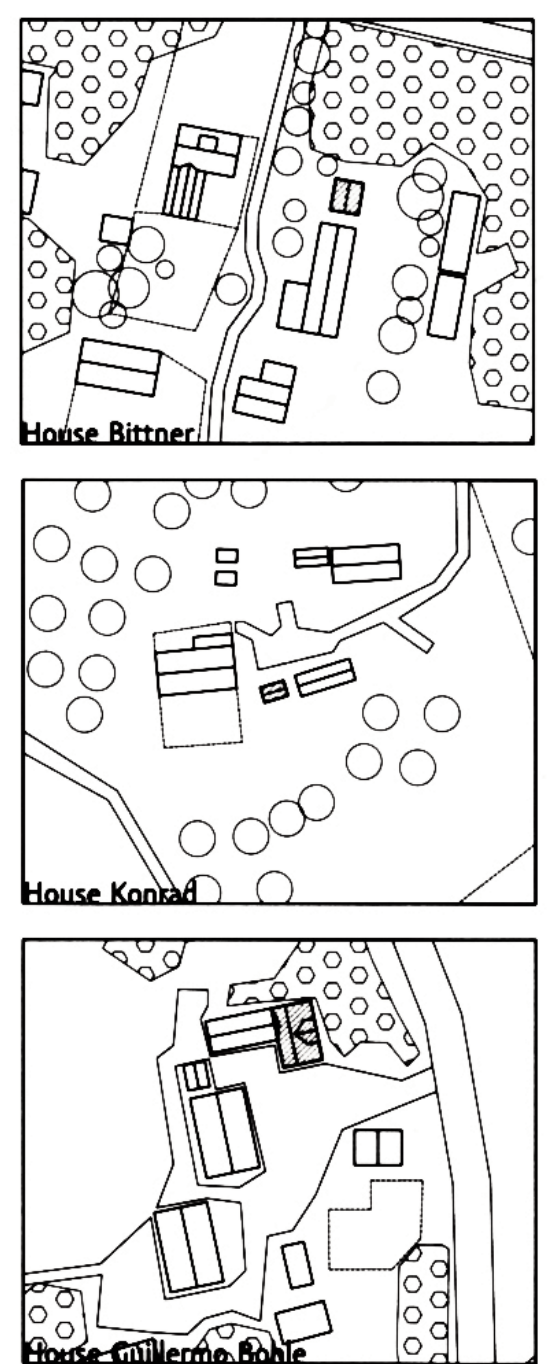
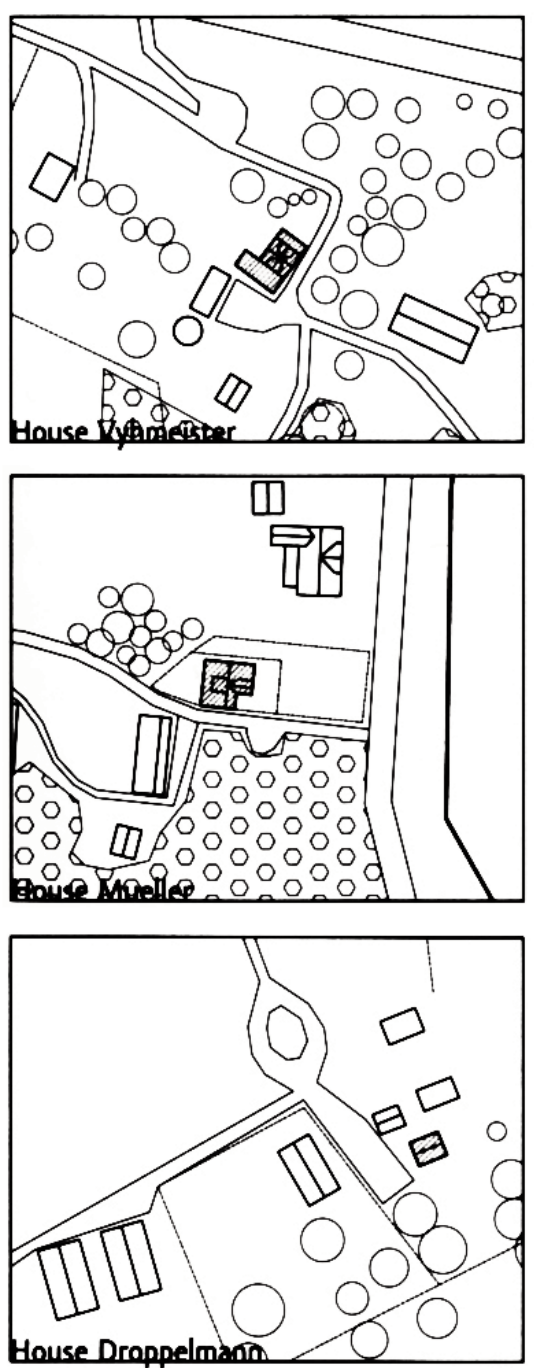
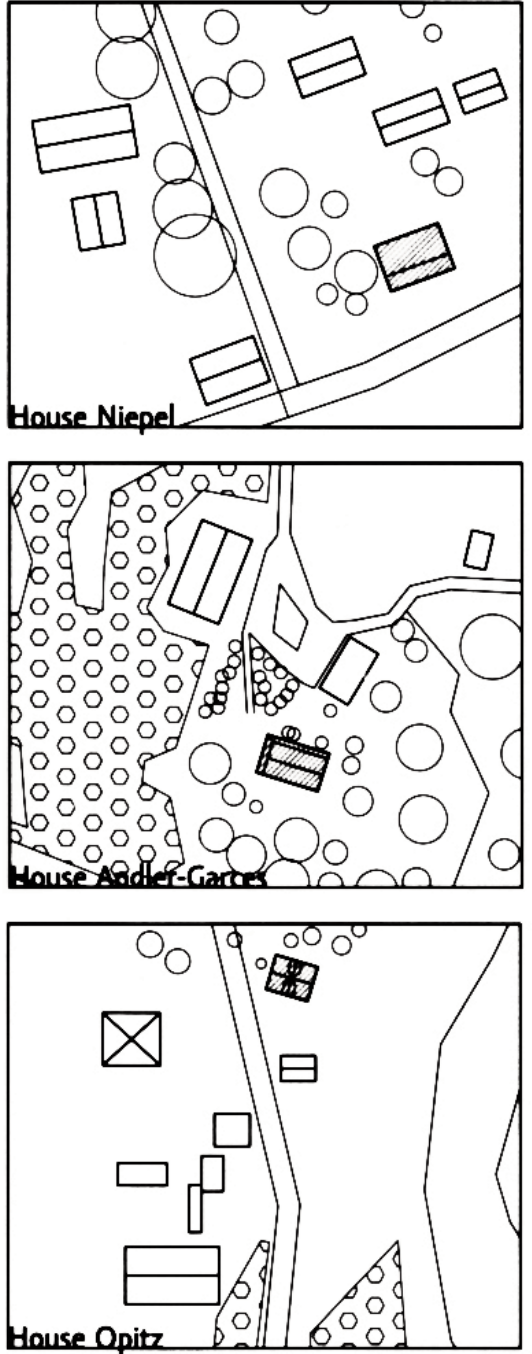
Figura 17. Calle Salvador, Puerto Varas, año 1885. Postal impresa (Archivo Fotográfico, Museo Histórico Nacional de Chile, PI-1536).

Figura 18. Vista de Puerto Octay, 1900. Postal impresa (Archivo Fotográfico, Museo Histórico Nacional de Chile, PI-1519).

Figura 19. Plaza de San Carlos de Chiloé en 1835. Lámina núm. 35 (Gay 1854).
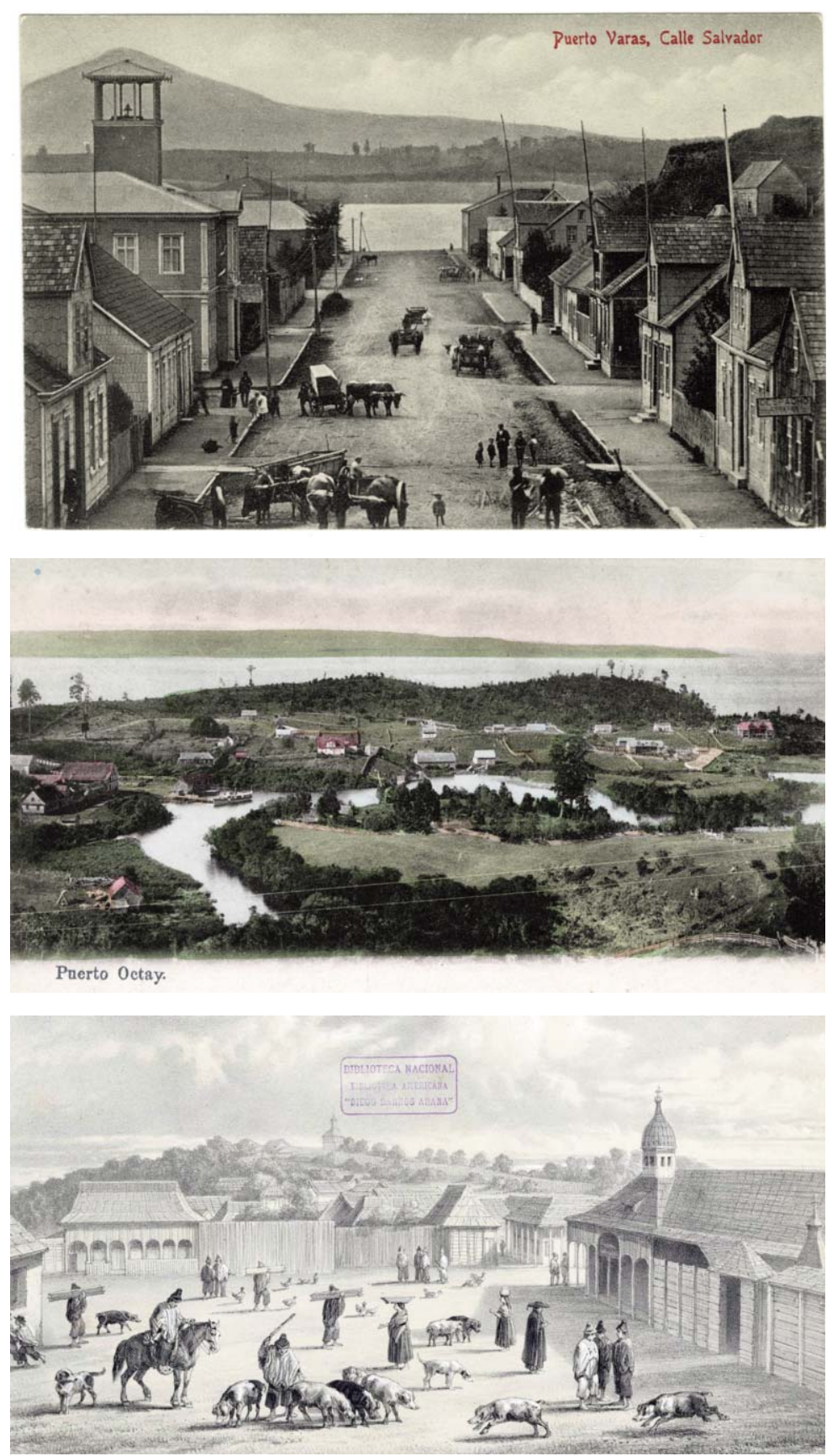

nas de ellas de pequeñas dimensiones. De estas cuatro eran con el sistema de blocao y el resto de entramado" (Cherubini 2016: 41). D'Alençon y Prado catalogaron en 2011 una vivienda de blockbau en Playa Maitén, edificada entre los años 18601879. A pesar de la abundancia de madera este sistema no llega a propagarse.

En la colonia del lago Llanquihue el volumen primario, con o sin mirador, suele incorporar modificaciones que no forman parte del proyecto inicial. Nos referimos principalmente a la existencia de un "corredor" situado en la fachada principal que discurre paralelo al faldón de cubierta. Este elemento se estructura de forma independiente, incorporándose enseguida a las primeras viviendas (Moser 2013). Los "cuerpos adosados", situados en la fachada posterior, se arman con la prolongación de la cubierta existente.

Estas características demuestran que las viviendas fueron edificadas sobre un proyecto inicial, lo que contribuyó a la propagación de tipos, y en su construcción participaron trabajadores procedentes de la isla de Chiloé (Blancpain 1985 y Peri 1989). En 1856 un colono ${ }^{20}$ registra:

"como elemento de ayuda se tomaban trabajadores de Chiloé; era dificil hacerse entender con ellos, ya que ninguno de nosotros dominaba el castellano. A veces se llegaba a los más graciosos mal entendidos, pero al final resultaba" (Peri 1989: 70).

Hay que hacer notar que los trabajadores procedentes de Chiloé ya contaban con una experiencia constructiva en madera previa a la llegada de los colonos germanos, tal como documentaron las expediciones de Charles Darwin (1829) y Claudio Gay (1835) a la isla. En sus ilustraciones se registran viviendas de madera de una altura, con muros de postería (sistema constructivo utilizado en Valdivia) y de postería labrada (Berg 2015) compuesto por pilares de madera con un rebaje vertical que recibe los tablones de madera dispuestos en horizontal. Las cubiertas son a dos o cuatro aguas, con acabado de tejuela de grandes dimensiones y con aleros o corredores en el exterior. Para la edificación de estas viviendas los carpinteros de Chiloé debieron contar con técnicas de ensamblaje minimas y posesión de herramientas especializadas. ${ }^{21}$ Para los elementos verticales que arman la postería labrada debieron utilizar el ensamble de caja y espiga para lograr su fijación a la solera inferior. Para el armado de los entramados horizontales debieron utilizar encuentros 


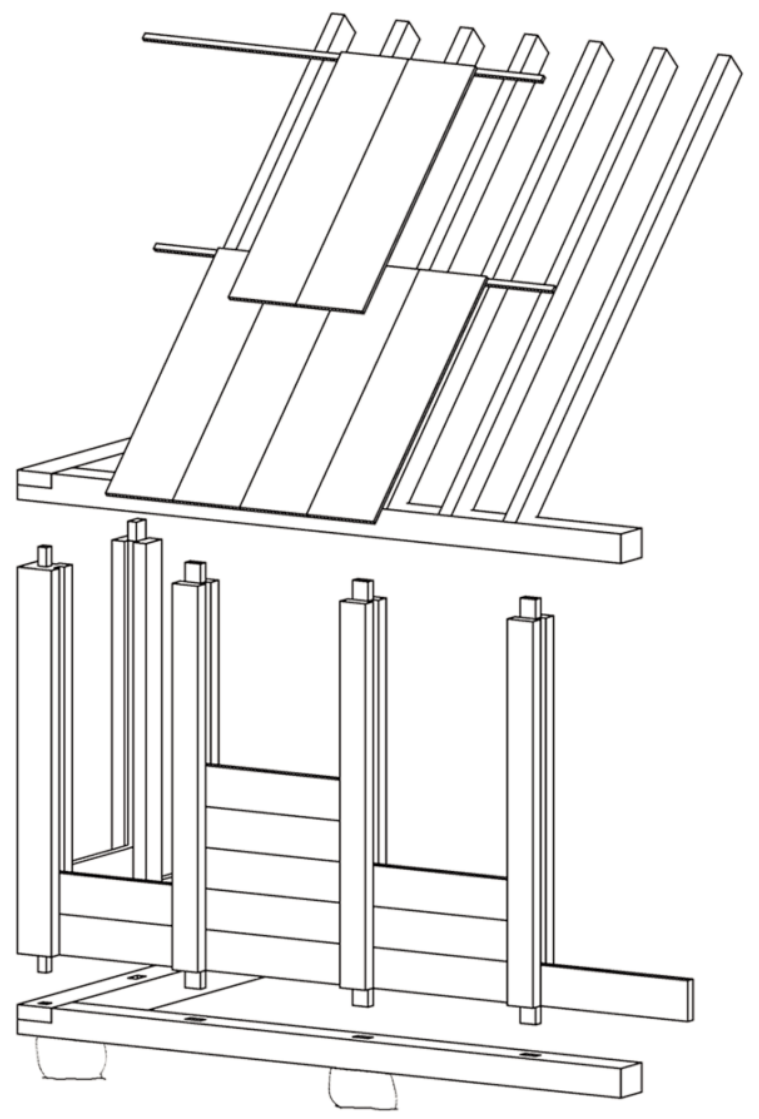

Figura 20. Esquema del sistema constructivo de posteria labrada utilizado en las viviendas de Chiloé en el siglo XIX (Jocelyn Tilleria G.).

Figura 21. Marcas de carpintero en vivienda de Puerto Octay. (D'Alençon y Prado 2013: 167). de media madera y, en casos particulares, ensambles de cola de milano como en las iglesias de Chiloé. Creemos que en la vivienda no fue necesario el uso del ensamble de rayo de Júpiter ya que las piezas de madera que se podian obtener de las especies nativas (alerce, coigüe y ciprés de las guaitecas) eran de grandes longitudes, por lo que no fue necesario recurrir a ensambles de mayor complejidad. Deducimos que el nivel de conocimiento constructivo alcanzado por los chilotes facilitó la rápida asimilación de las técnicas importadas por los colonos germanos, asî como el intercambio de conocimiento sobre especies madereras locales a los colonos.

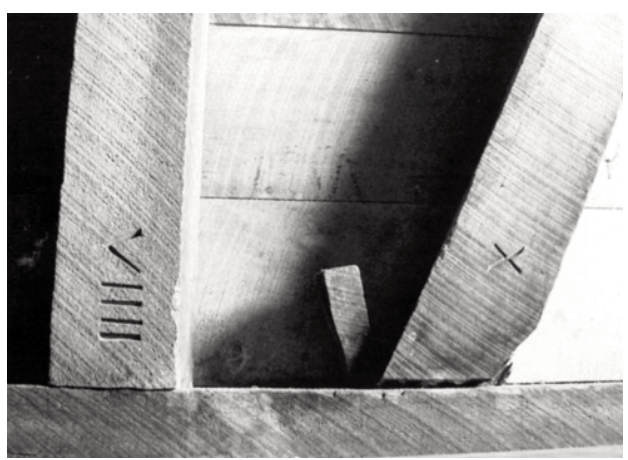

En la construcción de las viviendas de la colonia de Llanquihue se utilizó el sistema de marcas de carpintero ${ }^{22}$ que facilitaba la identificación de las piezas para su armado (Cherubini 2016, D'Alençon y Prado 2013), posiblemente también habria sido utilizado en Valdivia pero no hemos encontrado registro de su uso. Las puertas y ventanas llegaban listas para su instalación ya que eran armadas en talleres especializados como hemos registrado anteriormente. En muros, el principal revestimiento utilizado fue el tinglado, y en la cubierta la tejuela ${ }^{23}$ de alerce. Establecemos que en el uso de la tejuela se encuentra una transferencia constructiva por parte de los habitantes de Chiloé al ser un revestimiento expandido en la isla. ${ }^{24}$ También creemos que la pronta aceptación de este revestimiento se debe a que ya habia sido utilizado por los primeros colonos en Valdivia quienes comprobaron su impermeabilidad. El uso de la tejuela se expandió rápidamente a los muros, incorporando diseños más complejos, tal como registra la fotografia de Puerto Varas de 1885.

A partir de finales del siglo XIX el volumen primario incorpora nuevas variables, dos miradores o claraboyas y una altura más. Aparecen las cubiertas de cuatro aguas, y se incorporan como revestimiento las planchas de hierro galvanizado, primero en cubierta y después en muros. A partir de inicios del siglo XX con la llegada de la segunda oleada de emigrantes europeos, aparecen las viviendas tipo "chalet".

\section{Las viviendas de la colonización en las ciudades de Osorno y Puerto Montt}

Los núcleos urbanos de Osorno y Puerto Montt fueron, junto a Valdivia, las principales ciudades de la primera etapa de colonización. En ellas se concentró el comercio y la industria. Además, la mayoria de los colonos más ricos decidieron establecer en ellas su residencia, siendo sus viviendas una vitrina de las nuevas modas imperantes.

Osorno es un emplazamiento de origen hispano, abandonado a finales del siglo XVI y repoblado en el año 1796 por su situación estratégica y la necesidad de reactivación de la económica del sector.

Antes de la colonización decimonónica sus viviendas contaban con similitudes a las de Valdivia y Chiloé, caracterizadas por sus grandes cubiertas revestidas con tejuela, y la presencia de claraboyas y corredores exteriores. La albañileria de adobe se utilizó en Osorno en el siglo XVI y en su repoblación por orden del goberna- 

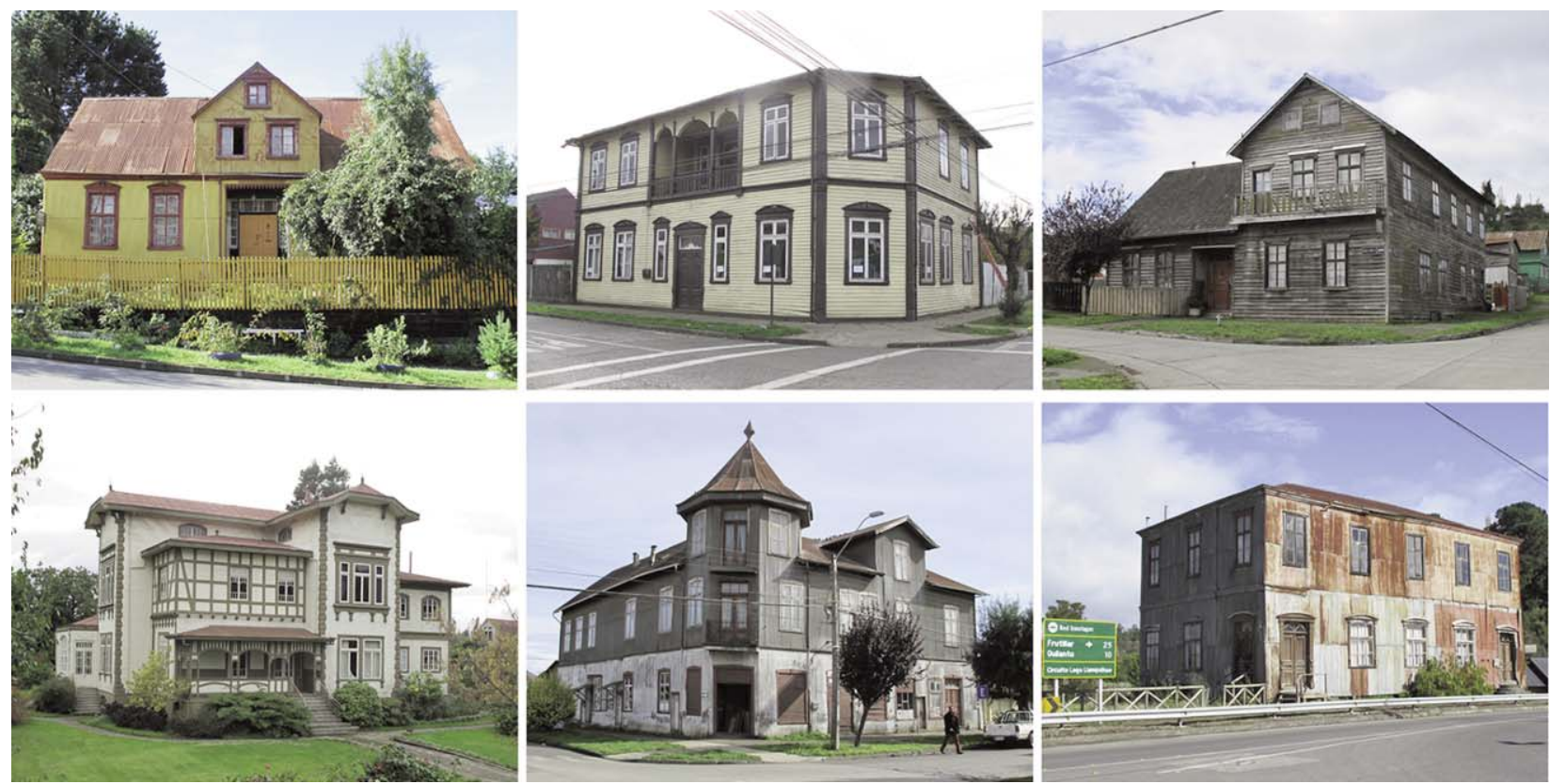

Figura 22. Viviendas de colonos alemanes edificadas en el siglo XX (Jocelyn Tillería).

Figura 23. "Der Platz von Osorno", año 1852, dibujo de Rodulfo Amando Philippi. Reconocemos similitudes con la arquitectura colonial hispana de Valdivia y Chiloé (Archivo fotográfico, dirección Museológica de la Universidad Austral de Chile. $N^{\circ}$ inv: $s / n)$. dor Juan Mackenna en 1797 (Sánchez 1948), pero el terremoto de 1837 destruyó gran parte de estas construcciones. Sus similitudes con las viviendas de Chiloé se deben principalmente por ser una de las procedencias de los ciudadanos con que fue repoblada en el siglo XVIII.

Los primeros colonos alemanes llegaron a Osorno en 1851 originarios de Rothenburgo (Blancpain 1985), Essen y Baviera (Sánchez 1948: 170). Su presencia transformó la imagen ruinosa que presentaba a mitad de siglo XIX.

Como en Valdivia, los inmuebles realizados por los colonos alemanes se emplazan de igual manera que las edificaciones existentes, se situaron en un extremo del solar con planta rectangular y lado más largo armando la fachada principal. Las primeras viviendas realizadas fueron del tipo "volumen primario" de uno o dos niveles, predominando la relación de altura de cubierta $1 / 2$ del total, el uso del mirador no fue tan expandido como en los emplazamientos ya estudiados, sin embargo, el uso del corredor exterior si, que a diferencia de las viviendas de Llanquihue formaba parte del proyecto inicial. En las viviendas de una altura el corredor se armaba con la prolongación del faldón de cubierta, y en las de dos alturas con el retranqueo total o parcial del nivel de acceso. También existen casos en que las viviendas de una altura realizan un retranqueo parcial de la fachada obteniendo un acceso porticado. La arquitectura alemana de la ciudad de Osorno conservó uno de los rasgos más

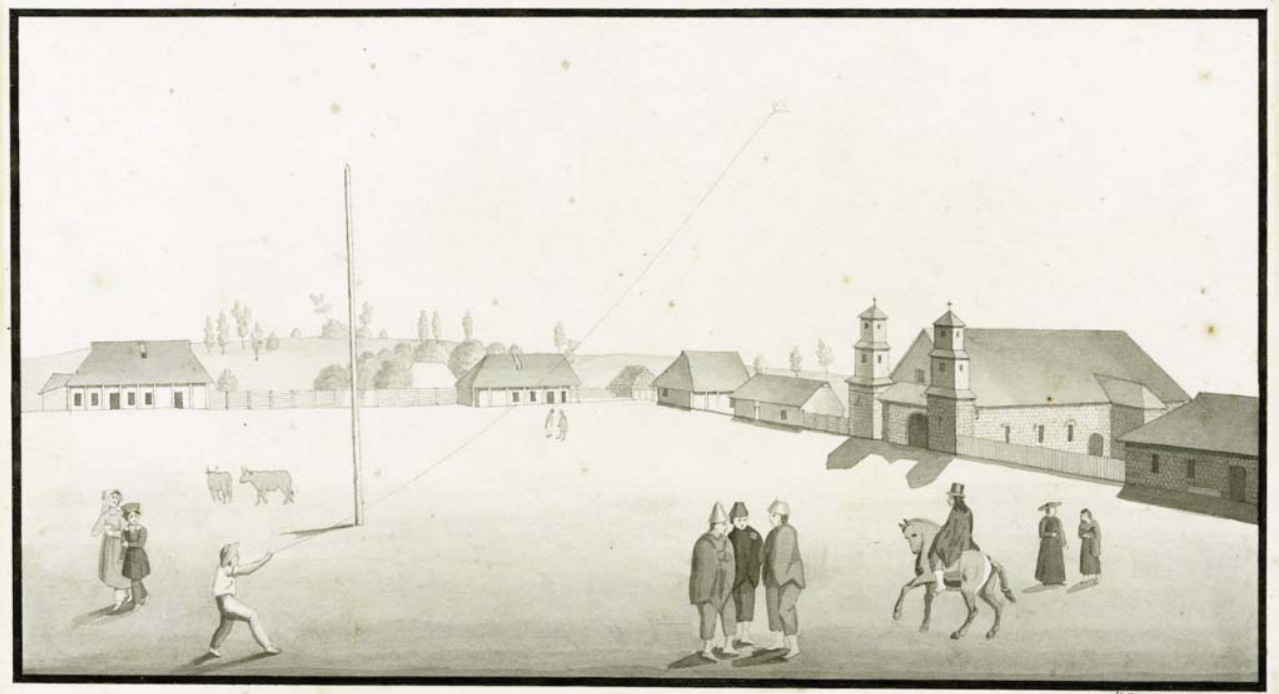

Dei Platz ven Osoino 
Figura 24. Imágenes de la ciudad de Osorno en 1900 (Guarda 1981: 14 y 18).

Figura 25. Dibujo perspectivo Isométrica de la casa Heissinger en Osorno, edificada en 1900. Con mirador y acceso porticado, se reconoce la tipología de planta con pasillo central. (Basaez, Montecinos y Salinas 1981: 26). característicos de la arquitectura del periodo hispano, el corredor.

Las viviendas se estructuran también con entramado de madera, sin innovaciones, "toda la enmaderación de las casas era trabajada con sierra i cepillo; los piés derechos estaban sobre soleras no enterradas en la tierra; los pisos eran de tablas i las ventanas tenian vidrios" (Philippi 1901: 332).

Finalizado el siglo XIX llega el ferrocarril a Osorno, se promueve el crecimiento de las exportaciones de trigo y ganado a Santiago y con ello el enriquecimiento de la ciudad. Como en las anteriores localidades estudiadas, aparecen las viviendas de dos niveles con cubierta a cuatro aguas y las de tipo chalet. En 1910 Osorno era considerada una ciudad rica digna rival de Valdivia (Blancpain 1985: 116).

Durante el primer periodo de colonización la ciudad de Puerto Montt fue el puerto más austral, fundado el 12 de febrero del año 1853, su origen se debe a la proximidad con el lago Llanquihue, la isla de Chiloé y su condición de puerto marítimo. En su trazado participaron los topógrafos alemanes Decher y Geisse (Blancpain 1985: 91), Decher fué uno de los autores de la parcelación de la colonia de Llanquihue. La traza utilizada fue la cuadrícula, dispuesta paralela a la costa, con calles de ancho minimo de 18 metros y manzanas de 50 metros de lado (Benavides, Pizzi y Valenzuela 1998: 51).

Los primeros alemanes desembarcaron en noviembre de 1852, antes de la fundación de la ciudad. Como para la mayoría el destino final era la colonia de Llanquihue, debieron esperar en Puerto Montt hasta que les fueran designadas sus propiedades. Algunas investigaciones plantean que este periodo de estadía les permitió conocer las características de la arquitectura que se estaba forjando en la naciente ciudad. Creemos que entre los primeros colonos no debió ejercer mucha influencia, ya que las principales edificaciones se levantaron en 1853, cuando la colonización del lago ya se había iniciado (1852). Las referencias que pudieron ser tomadas de la arquitectura de Puerto Montt fueron cuando esta logra consolidarse como un importante centro de intercambio comercial y abastecimiento de la colonia de Llanquihue, siendo Valdivia el punto de referencia constructivo durante los inicios de la colonia.

Las viviendas de la ciudad de Puerto Montt edificadas durante el primer periodo de la colonización se emplazan en un extremo del solar, de igual modo que en las ciudades de Valdivia y Osorno, con fachada principal a pie de calle. Esta situación urbana está dada por la ordenanza municipal de 1854 (Cherubini 2016: 67). Predo-
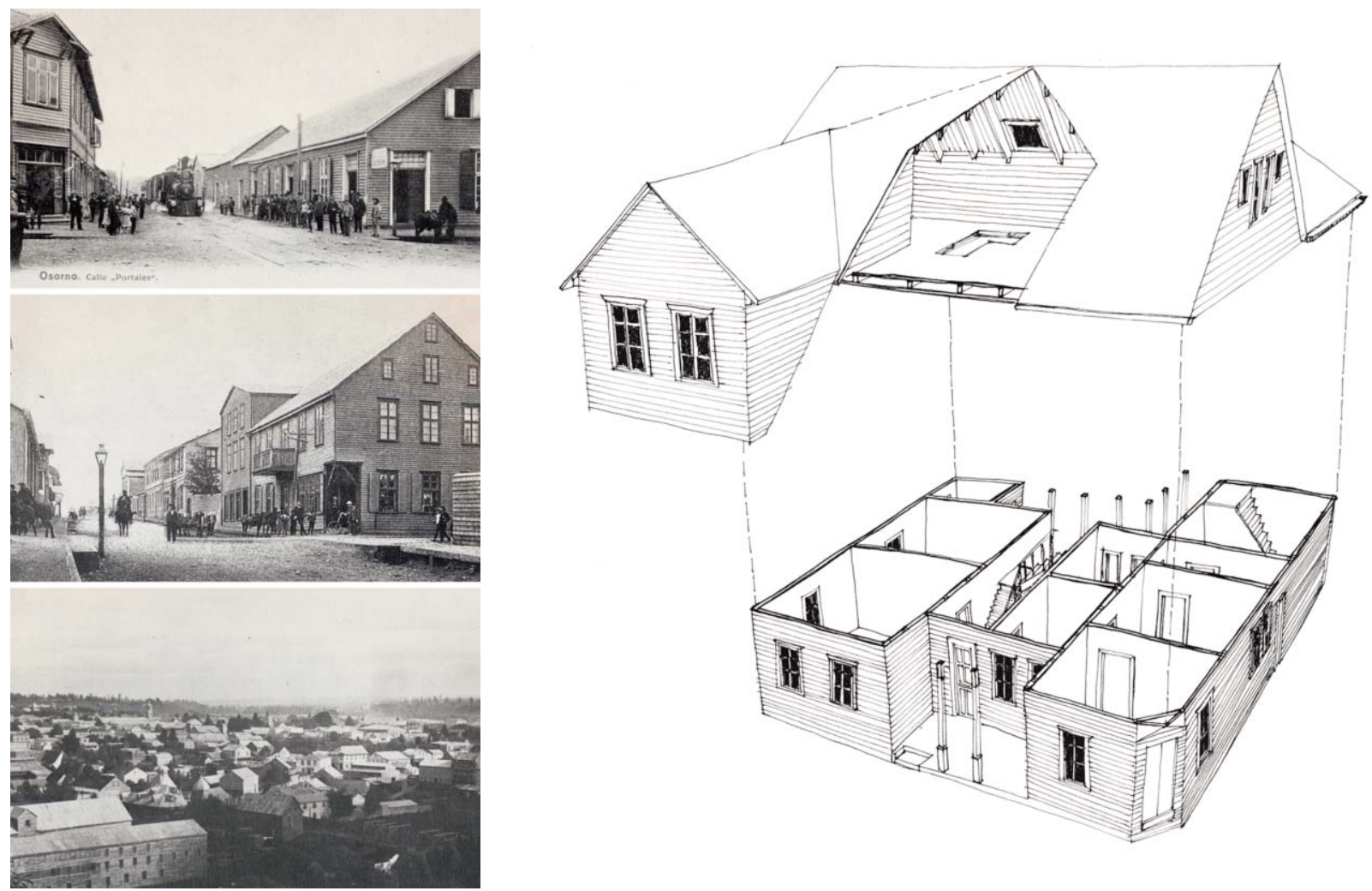
Figura 26. Plano de Puerto Montt ó Melipulli de 1859. Realizado por Francisco Vidal Gormáz. Biblioteca Nacional de Chile. (Ref. web 1).

Figura 27. Vista de Calle Varas en Puerto Montt, año 1893. Identificamos cons trucciones del tipo volumen primario con y sin mirador. Fotógrafo: Germán Wieder67). hold. (Cherubini 2016 :

minan las viviendas del tipo "volumen primario" de una y dos alturas, y las de "volumen primario con mirador", como en Valdivia la altura de la cubierta puede ser igual o mayor que el primer nivel, la altura de cubierta se encuentra en una relación de $1 / 2$ a $3 / 5$ de la altura total del inmueble. Las pendientes varian entre un $70 \%$ y $90 \%$. Las viviendas fueron edificadas con entramado de madera, como ya era tradición, y para su construcción se contó con trabajadores procedentes "de las islas de Maillén, Huar y de las caletas de Huelmo y de Chiloé" (Cherubini 2016: 27), que contaban con experiencia en construcción en madera.

Las actuales investigaciones de Cherubini reconocen la importante participación de un colono alemán en la formación de la arquitectura de Puerto Montt, el carpintero Matthias Doggenweiler, autor de los principales edificios públicos de la ciudad. Doggenweiler desembarcó en Puerto Montt en 1852 procedente de Württemberg e inicia en 1853 las obras de la Gobernación y Catedral de la ciudad. Cherubini plantea que este carpintero estableció contacto en Valdivia con Wilhelm Frick, quien pudo
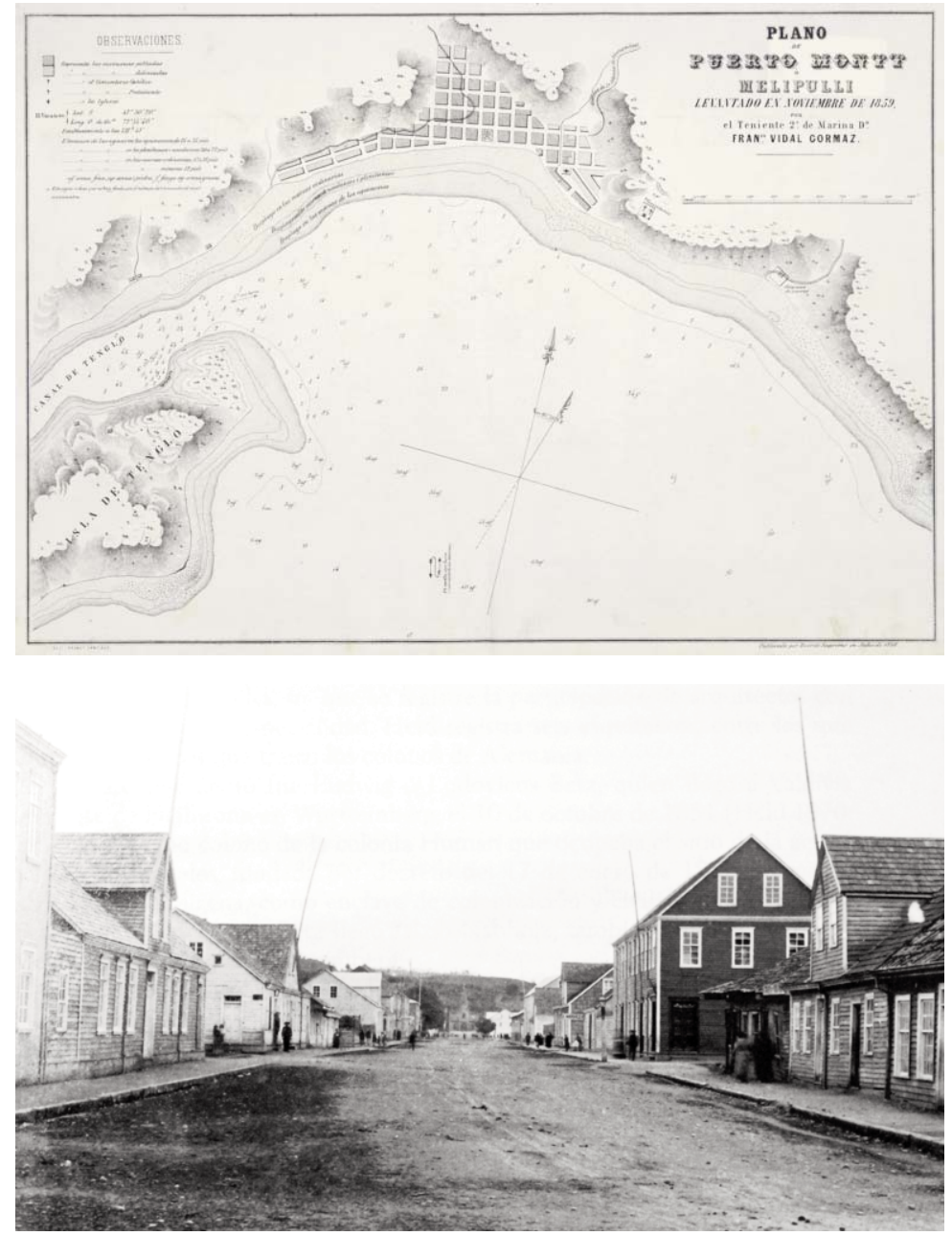

transmitir su experiencia constructiva en la ciudad de Valdivia y que Doggenweiler utilizó de guía. Lo cierto es que son indudables las similitudes arquitectónicas entre ambas ciudades.

El revestimiento utilizado en muros fue tinglado, y en cubierta tejuela, a partir de finales del siglo XIX, como en el resto del territorio de la colonización, se expande el uso de las planchas de hierro galvanizado. Y desde un punto de vista formal, también aparecen las viviendas de dos plantas, las cubiertas a cuatro aguas, y las viviendas de tipo chalet.

\section{La "Alemania Austral": referencias a la cultura germana en Chile}

Los trabajos de Jean-Pierre Blancpain sobre la inmigración alemana en Chile dan prueba de que los colonos adoptaron una actitud conservadora frente a la sociedad chilena, y que en todo momento cultivaron la herencia germana (Blancpain 1985). Para mantener el vínculo con los territorios de procedencia, se fomentó la permanencia del idioma y se crearon escuelas, en contraste con los altos niveles de analfabetismo que existian en el país. Puede dar una idea la existencia en Chile de treinta escuelas alemanas en 1914. También se estableció la tradición de realizar viajes a Alemania para mantener el contacto con las raíces, y los más jóvenes aprovecharon esta experiencia para proseguir sus estudios o para buscar pareja con la que contraer matrimonio. En este sentido, hay que destacar como el núcleo familiar tuvo un importante rol en la conservación de las tradiciones. Las familias se caracterizaron por tener un elevado número de hijos. En Frutillar, por ejemplo, "los matrimonios celebrados entre 1858 y 1900 tuvieron una fecundidad media de 6,5 hijos por familia" (Blancpain 1970: 29). Además, los matrimonios solian realizarse entre integrantes de la propia colonia. Creemos que en la formación de esta dinámica de relaciones influyó la situación misma de aislamiento que tuvo esta región hasta el año 1880, fecha hasta la cual el país se encontraba fragmentado por el territorio de la Araucanía, que comprende los casi 200 kilómetros de frontera intermedia que impedian la comunicación terrestre con las principales ciudades del centro del país.

Esta situación de arraigo a las tradiciones no impidió sin embargo las relaciones con la población de nacionales durante la primera etapa de colonización. Estas relaciones fueron principalmente laborales y están marcadas por las diferencias lingüísticas y culturales, y seguramente también por los propios conocimientos técnicos. 

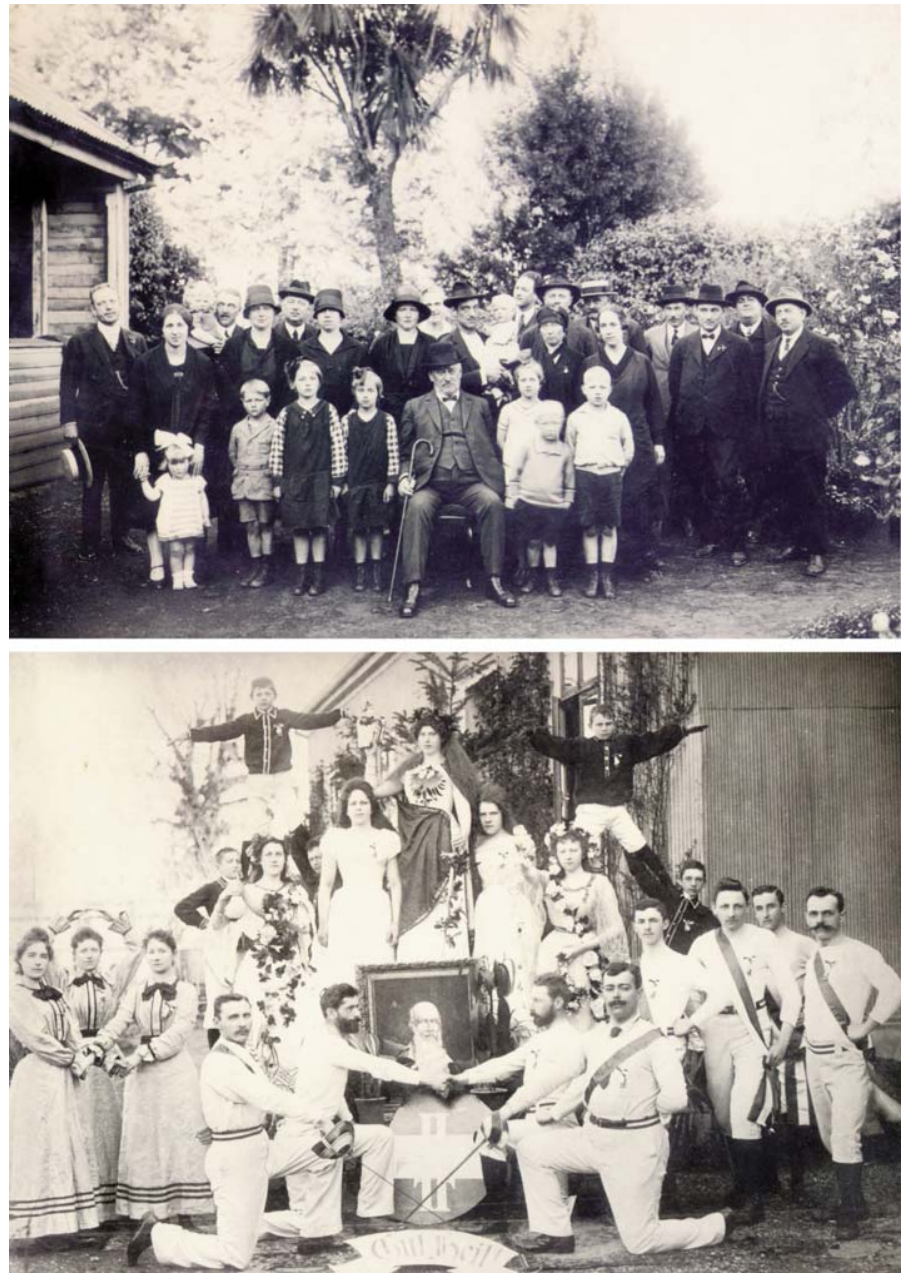

Con relación a la propiedad rural, rápidamente se gestionaron bajo una mirada de pertenencia. Las parcelas fueron transmitidas de generación a generación, y raramente fueron vendidas, lo que permitió configurar un territorio con una marcada identidad. A inicios del siglo XX la explotación de los terrenos seguía siendo realizada por propietarios que eran descendientes de los primeros colonos (Blancpain 1985).

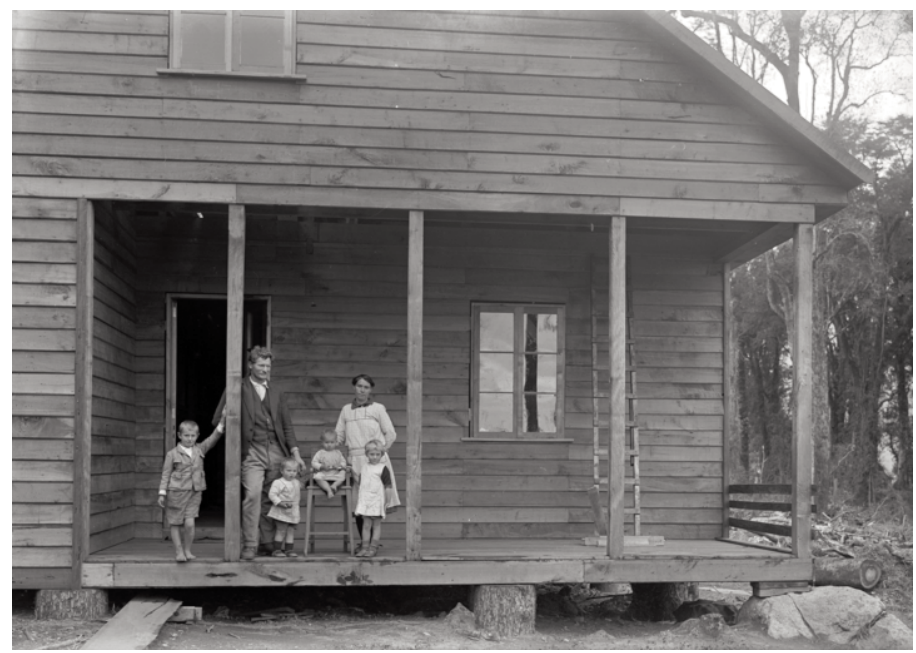

Las viviendas generadas son el resultado de variables espaciales y constructivas importadas por los colonos, que se adaptaron a los requerimientos y posibilidades que ofrecía este territorio. Chiloé jugó un papel importante al participar de la formación de las colonias del lago Llanquihue y Puerto Montt. Gracias a su experiencia constructiva previa, formó parte de un proceso de transferencia entre técnicas locales y extranjeras, y contribuyó a su difusión también en la segunda fase de colonización. Cherubini considera a los habitantes de Chiloé como "vehículos de trasmisión cultural" (Cherubini 2016: 14).

La adaptación de los tipos europeos importados ha quedado demostrada en la simplificación de la técnica constructiva del fachwerk, y en la normalización espacial y formal de las nuevas construcciones. Sobre la simplificación del fachwerk, las investigaciones de D'Alençon y Prado concluyen que se encuentran en la eliminación de "travesaños (Knagge), encintados (Kopfband) o correas (Fußband)" (D'Alençon y Prado 2013: 131), además del uso reducido de soleras (Riegel), utilizado solamente para el armado de vanos "en contraste con los casos europeos, en que se usan sistemáticamente" (D'Alençon y Prado 2013: 131), y a los ya mencionados espacios entre entramados de muro (gefach), que no se encuentran rellenos.

La normalización espacial está dada por las innovaciones en la planta de las viviendas que incorporan más habitaciones para individualizar el programa arquitectónico por recinto, en contraste con las viviendas anteriores con un reducido número de habitaciones y programas mixtos. Mientras que las normalizaciones volumétricas y formales se encuentran en el uso de la simetría, y la aparición de relaciones geométricas en su volumen y en la composición de las fachadas.

Conocidas las regiones de origen de los colonos, se han buscado relaciones entre su arquitectura tradicional y la resultante en las colonias chilenas, sin encontrar mayores vinculaciones que las ya citadas. Concordamos además con lo postulado en la publicación de D'Alençon y Prado en que plantea la existencia de "una importación selectiva", y además establecemos que en este proceso de selección el uso del entramado de madera es el mejor ejemplo, dado por la disponibilidad de material para su construcción, su rápido armado, ser una técnica parcialmente ya conocida por los habitantes de Chiloé, no requerir de trabajos de excavación para su construcción (solo requiere de cimentación aislada nive- 
Página anterior. Figura 28 (doble). Familia alemana de Valdivia en 1920 y grupo de esgrimistas de la colonia alemana de Valdivia en 1900. Fotógrafos no identificados. Archivo fotográfico Ellynor Fehrenberg del Centro Cultural Austral, Valdivia. (Alvarado y Matthews 2006: 43 y 46).

Página anterior. Figura 29. Familia de colonos alemanes, año 1930. Fotógrafo: Einar Altschwager (Archivo Fotográfico, Museo Histórico Nacional de Chile, PFB-1054).

Figura 30. Viviendas que conservan invariantes de la arquitectura de los colonos construidas en la segunda mitad del siglo XX y situadas en las localidades de La Unión, Río Bueno y Puerto Octay (Jocelyn Tillería G.). lada) y su resistencia a los sismos, dado por la flexibilidad de la estructura. Condiciones que contribuyeron a su rápida expansión en la primera y segunda etapa de la colonización.

\section{La vernacularización de la arquitectura de la colonia alemana: su influencia en la arquitectura tradicional entre Valdi- via y Puerto Montt}

La arquitectura generada en el primer periodo de la colonización europea en Chile (1846-1875) fijó las bases de una tradición constructiva expandida por el sur del país que ha perdurado hasta hoy. Durante la segunda oleada de la inmigración europea (1882-1900), en la cual se completó la ocupación de los territorios de la colonización, se continuaron edificando viviendas con los invariantes arquitectónicos del primer periodo que fueron incorporando nuevas variables asociadas a las llegadas de las nuevas modas.

En las ciudades estudiadas y sus territorios próximos es posible reconocer inmuebles edificados con posterioridad al desarrollo de la colonización oficial que aún conservan invariantes de esta arquitectura y que fueron levantados por constructores anónimos que se encargaron de mantener y propagar estas nuevas maneras de habitar y construir. Es decir, nos encontramos frente a un verdadero proceso de vernacularización de las arquitecturas importadas de la Europa Central. Además, hemos podido comprobar la permanencia de los invariantes arquitectónicos formados en la ciudad de Valdivia, demostrando que aquí se encuentra el punto de partida de la arquitectura de la colonización austral del país.

Para comprobar la permanencia de estos invariantes se han catalogado viviendas edificadas en la primera mitad del siglo $\mathrm{XX}$, muy posteriores al periodo de inmigración europea. Son, como hemos dicho, inmuebles que no fueron edificados por colonos alemanes, lo que nos permite demostrar la influencia que tuvieron estas arquitecturas en la formación de la vivienda tradicional. Los inmuebles catalogados se sitúan en los territorios de la primera etapa de colonización, entre Valdivia y Puerto Montt, en núcleos urbanos que cuentan con una menor presión urbana y que conservan un mayor número de ejemplos de arquitectura tradicional como La Unión, Río Bueno y Puerto Octay. 25

Entre los casos catalogados hemos comprobado que las viviendas continúan siendo edificadas en un extremo del solar, con fachada principal a pie de calle, como en el periodo colonial hispano. Las diferencias se encuentran en que las viviendas se sitúan de forma aislada y en las ciudades de Puerto Octay y Rio Bueno algunas cuentan con antejardin.

Predominan las viviendas del tipo "volumen primario", de un nivel con planta rectangular y con fachada principal armada por el lado más largo de la edificación. El volumen primario también se modifica, dado por la incorporación de nuevas varia-

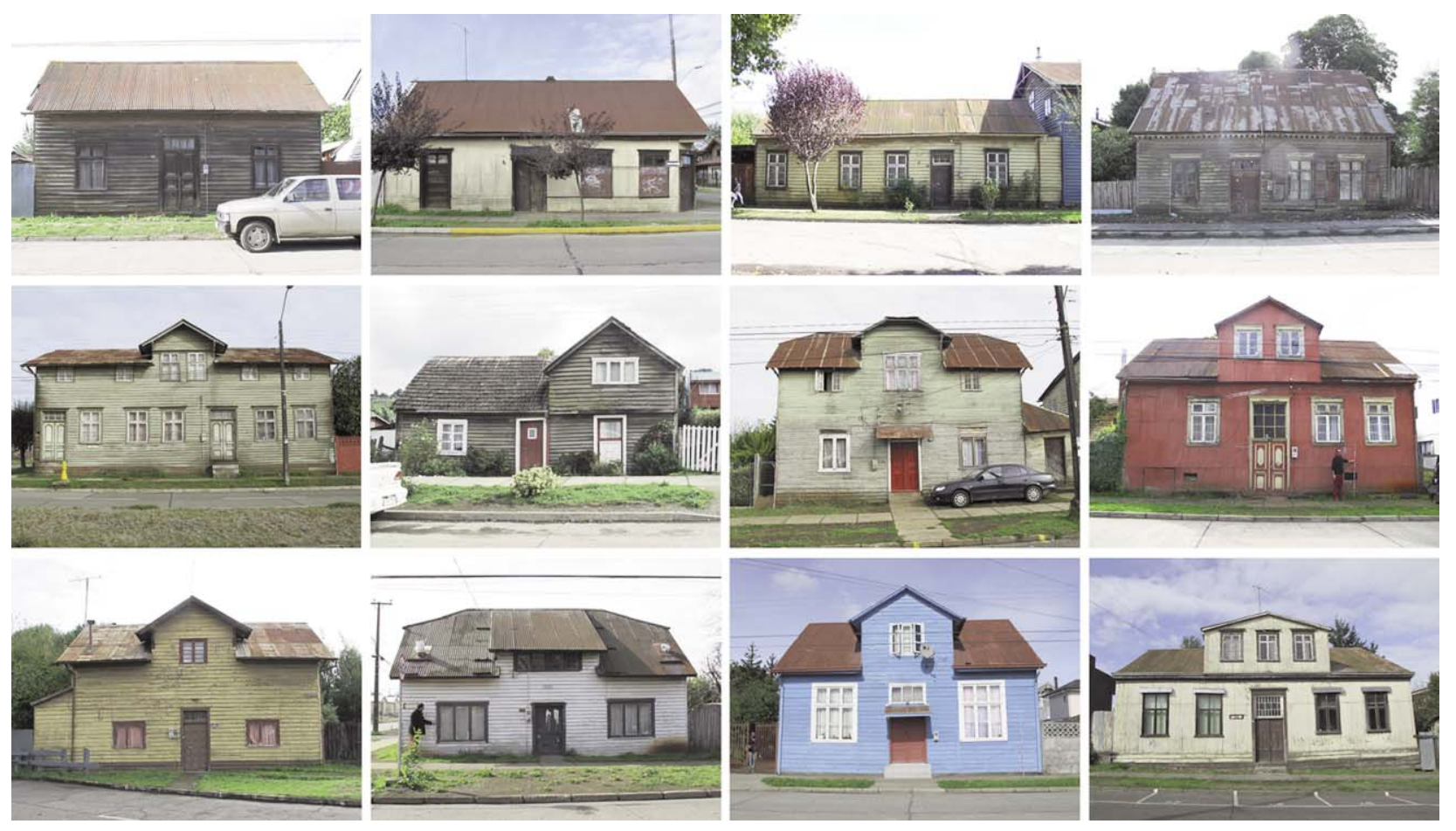


bles como la esquina en chaflán correspondiente a edificaciones situadas en el encuentro de dos calles y con programa mixto (residencial y comercial). En la localidad de Puerto Octay el volumen primario suele incorporar un corredor en fachada principal que no es parte del proyecto inicial. Y en Río Bueno el volumen primario suele ser de dos alturas. Las edificaciones realizadas con proximidad a mitad del siglo XX, presentan las mayores modificaciones al volumen primario. En las tres localidades estudiadas encontramos viviendas conformadas por el tipo de "volumen primario con mirador", pero en menor proporción que la tipología anterior.

Sobre la composición de fachada, predominan las que tienen un acceso destacado. Y en las viviendas de La Unión prima la simetría. En todas las localidades los vanos siempre se encuentran alineados por nivel, y en la mitad de las localidades catalogadas los vanos se encuentran cercados con ornamentación que hace referencia al universo ornamental de raíz neoclásica. El entramado de madera continúa siendo el principal sistema constructivo, y el revestimiento de muros más extendido es el tinglado, y en menor proporción la tejuela. El uso de las planchas de hierro galvanizado acanaladas se encuentra en todas las cubiertas, y su uso como revestimiento de muros está presente en las viviendas de La Unión, y en Puerto Octay en escasas ocasiones.

A pesar de las similitudes que se han encontrado y definido, cada una de las localidades catalogadas presenta sus propias individualidades. A modo de ejemplo, puede resaltarse como las viviendas de Río Bueno incorporan aleros armados con jabalcones, mientras las viviendas de Puerto Octay corredores, o como las fachadas que cuentan con mayor ornamentación se localizan en Río Bueno y La Unión.

Pasado más de un siglo del periodo en que se establecieron estos tipos arquitectónicos de la colonización europea, se siguen edificando en el sur de Chile viviendas con invariantes propias de esta arquitectura de la tradición. A pesar de la incorporación de las nuevas técnicas constructivas y de los materiales de construcción que las acompañan, las variables formales y el uso sistemático de la madera, siguen siendo hoy una parte substancial del imaginario de la arquitectura de las ciudades del sur del pais.

No quisiéramos terminar este artículo sin una reflexión sobre el estado de conservación de este valioso patrimonio de la arqui- tectura chilena. Durante los años 1980 y 1981 las Escuelas de Arquitectura de la Universidad de Chile y de la Pontificia Universidad Católica de Chile realizaron distintos estudios sobre la arquitectura tradicional en las actuales regiones de Los Ríos y Los Lagos, y dejaron registro de los inmuebles realizados durante esta última etapa de la colonización europea del sur del país. Para el desarrollo de los trabajos de campo que han acompañado este trabajo, se ha podido comprobar que una parte considerable de los casos estudiados y catalogados entonces hace menos de cuarenta años, se encuentran hoy en alto riesgo de desaparición o sencillamente ya han desaparecido. Para el caso de la ciudad de Valdivia, del total de inmuebles catalogados por la Escuela de Arquitectura de la Pontificia Universidad Católica de Chile, un trabajo coordinado en su dia por el eminente arquitecto e historiador de la arquitectura Gabriel Guarda,26 se han conservado un $75 \%$ de los inmuebles catalogados. Sin embargo, en la ciudad de Osorno, en la que los trabajos fueron realizados por la Universidad de Chile $^{27}$ y coordinados por el destacado arquitecto y restaurador Hernán Montecinos, se ha podido comprobar que más del $40 \%$ de los casos estudiados lamentablemente han desaparecido. Finalmente, para el caso de la ciudad de Puerto Montt, en que la investigación fue realizada por Juan Benavides, Marcela Pizzi y María Paz Valenzuela, y cuyos resultados se registran en la publicación Ciudades y arquitectura portuaria: los puertos mayores del litoral chileno, 28 hay que señalar que a veinticinco años del desarrollo de aquellos trabajos ya han desaparecido más del $50 \%$ de los inmuebles identificados de valor, no habiendo sido posible localizar un $13 \%$ adicional. Por ello, es importante tomar conciencia del grave riesgo de conservación en que se encuentra este frágil patrimonio arquitectónico de la tradición a pesar del gran valor históricoconstructivo que tiene para Chile.

\section{Notas}

1. La Confederación Alemana estaba formada en 1845 por distintos territorios integrados hoy en Alemania, Polonia, la República Checa y Austria.

2. Se han estudiado principalmente las obras de los fotógrafos de la colonización alemana en Chile: Christian Enrique Valck (1826-1899), Rodolfo Knittel (1876-1958), Germán Wiederhold (1870-1949) y Odber Heffer (1860-1945). Se han consultado, además, fotografias y postales de autor anónimo del Archivo Fotográfico del Museo Histórico Nacional de Chile y del Archivo Fotográfico de la Dirección Museológica de la Universidad Austral de Chile.

3. El trabajo se inscribe en el marco de la tesis doctoral titulada "Forma y construcción de la 
vivienda tradicional en Chile. Tipos y transformaciones de los modelos de vivienda europeos (1541-1931)", que se desarrolla en el programa de doctorado en Patrimonio Arquitectónico de la Escuela Técnica Superior de Arquitectura de la Universidad Politécnica de Madrid.

4. Según establece el artículo $4^{\circ}$ de la Ley colonización del 18 de noviembre de 1845 .

5. En este artículo no trataremos el proceso de colonización de la región de Magallanes ya que su situación de aislamiento hizo que no se desarrollara de forma paralela al restante territorio de colonización.

6. Basado en las investigaciones de Held (1970), Blancpain (1974) y D'Alençon y Prado (2013).

7. Terremotos de 1835 y 1837.

8. Diplomático chileno considerado precursor de la colonización alemana en Chile. En 1850 fue nombrado Agente de la colonización de Valdivia y Llanquihue.

9. Naturalista alemán hermano de Bernhard Eunom Philippi.

10. Visitan la ciudad de Valdivia en el año 1835 Las observaciones quedaron registradas en el tomo II de la publicación: Darwin, Charles; Fitzroy, Robert y King, Philip Parker. 1839 Narrative of the surveying voyages of His Majesty's ships Adventure and Beagle between the years 1826 and 1836: describing their examination of the southern shores of South America and the Beagle's circumnavigation of the globe: in three volumes. London: Henry Colburn.

11. Estructura transversal a linea de cubierta, que se arma de la prolongación del muro, con cubierta a dos aguas.

12. De menor dimensión que el mirador, y que solamente otorgan luz al espacio bajo cubierta.

13. Abogado, ingeniero, naturalista, compositor, entre otras ocupaciones.

14. También denominado "desván".

15. A modo de ejemplo, para una parcela de 100 cuadras las dimensiones del terreno son de 5 cuadras de ancho $(625 \mathrm{~m})$ por 20 cuadras de largo $(2.500 \mathrm{~m})$ (D'Alençon y Prado 2013: 118).

16. Se le concede el título de Municipio el 22 de diciembre de 1891 .

17. Se le concede el título de Municipio el 30 de diciembre de 1925.

18. Se le concede el título de Municipio el 19 de junio de 1968.

19. Las condiciones climáticas de los primeros años de la colonia del lago Llanquihue impidieron el cumplimiento de los plazos exigidos, el estado de Chile decide postergarlos sin aplicar multas.

20. Ver Anuario de la Liga Chileno-Alemana de 1917, relato de Siebald de Michael traducido por Enrique Kinzel.

21. Hachas, azuelas, martillos, mazos, sierras, escoplos, formones, y taladros (Cherubini 2016).

22. Denominados abbundzeichen, técnica constructiva utilizada en Alemania hasta finales del siglo XIX, adaptada por los colonos alemanes en Chile para señalar las principales piezas estructurales (D'Alençon y Prado 2013. 211).

23. En investigaciones de Johanna Moser, se reconoce una relación entre el tamaño de la tejuela y su antigüedad "tejas de más de $1 \mathrm{~m}$ de largo se documentaron en casa tempranas..., mientras que las tejas de las casas construidas después son de entre 30 y $40 \mathrm{~cm}$ de largo." (Moser 2013: 221-222).

24. Concordamos con lo planteado por Moser (2013) y Cherubini (2015).

25. Los trabajos de catalogación se realizaron en abril del año 2015. Aunque fueron documentados un mayor número de casos, se realiza- ron 23 fichas correspondientes a las viviendas con las menores alteraciones al volumen original. Muchos de los casos de interés se encontraban en ruina o con alteraciones que impedian su lectura, lo que demostró el riesgo de conservación en que se encuentra la vivienda tradicional en esta parte del país.

26. Los trabajos realizados por los estudiantes de la cátedra de Historia Urbana de dicha Universidad quedaron registrados en la publicación: Guarda, Gabriel O.S.B. 1980. Conjuntos urbanos histórico arquitectónicos, Valdivia, s. XVIII-XIX. Santiago de Chile: Ediciones Nueva Universidad, Pontificia Universidad Católica de Chile.

27. Los resultados de la investigación han quedado registrados en la publicación: Basaez, Patricio; Montecinos, Hernan y Salinas, Ignacio. 1981. Arquitectura tradicional de Osorno y La Union. Santiago de Chile: Facultad de Arquitectura y Urbanismo, Universidad de Chile.

28. Proyecto FONDECYT 962, años 1991-1992. Universidad de Chile. Facultad de Arquitectura y Urbanismo.

\section{Bibliografia}

Alvarado, Margarita y Matthews, Mariana. 2005 Los pioneros Valck. Un siglo de fotografia en el sur de Chile. Santiago de Chile: Pehuén.

Alvarado, Margarita y MATthews, Mariana. 2006. Rodolfo Knittel: fotógrafo y viajero en el sur de Chile. Santiago de Chile: Pehuén.

Basaez Yau, Patricio; Montecinos Barrientos, Hernan y Salinas JaQue, Ignacio. 1981. Arquitec tura tradicional de Osorno y La Union. Santiago de Chile: Facultad de Arquitectura y Urbanismo, Universidad de Chile.

Benavides Courtois, Juan; Pizzi Kirschbaum, Marcela y Valenzuela Blossin, María Paz. 1998. Ciudades y Arquitectura Portuaria: los puertos mayores del litoral chileno. Santiago de Chile: Editorial Universitaria.

Berg Costa, Lorenzo. 2015. Rastreo de las influencias y precedentes en la composición arquitectónica de las iglesias tradicionales de Chiloé. Madrid: E.T.S. de Arquitectura de la Universidad Politécnica de Madrid. Tesis doctoral inédita.

BlancPain, Jean Pierre.1970. La Tradición Campesina Alemana en Chile. Boletín de la Academia Chilena de la Historia, núm. 81. Santiago de Chile: Imprenta Camilo Henriquez.

BlANCPAIN, Jean-Pierre. 1974. Les Allemands au Chili (1816-1945). Köln: Böhlau Verlag.

BLANCPAIN, Jean-Pierre. 1985. Los alemanes en Chile (1816-1945). Traducción de Luis Enrique Jara "Les Allemands au Chili", Colección HistoHachette. Santiago de Chile: Editorial Universitaria.

BRIONES LUCO, Ramón. 1898, Glosario de colonización: Leyes, Decretos y demás antecedentes relativos al despacho de Colonización, hasta el 31 de diciembre de 1897. Santiago de Chile: Imprenta Moderna.

Cherubini ZAnetel, Gian Piero. 2016. La escuela de carpinteros alemanes de Puerto Montt, su formación e influencia más allá de las fronteras. Santiago de Chile: Editorial Universitaria.

DARwin, Charles; Fitzroy, Robert y KInG, Philip Parker. 1839. Narrative of the surveying voyages of His Majesty's ships Adventure and Beagle between the years 1826 and 1836: describing their examination of the southern shores of South America and the Beagle's circumnavigation of the globe: in three volumes: proceedings of the second expedition, 1831-1836, under the command of captain Robert Fitz-Roy. Vol, II. London: Henry Colburn. 
D Alencon CAstrillón, Renato y Prado García, Francisco (ed.). 2013. Constructores inmigrantes: Transferencias de Alemania a Chile 1852 1875. Santiago de Chile: Ediciones Universidad Católica de Chile.

DoмeYкo, Ignacio. 1846. Araucanía y sus habitantes: recuerdos de un viaje hecho en las provincias meridionales de Chile, en los meses de enero y febrero de 1845. Santiago de Chile: imprenta chilena.

Gay, Claudio. 1854. Atlas de la historia fisica y politica de Chile. Tomo I. Paris: Imprenta de E. Thunot y $\mathrm{C}^{\mathrm{a}}$. P.

GREve, Ernesto.1940. Don Guillermo Frick y Eltse (1813-1905). Revista Chilena de Historia y Geografia, tomo LXXXVIII: 29-93.

GUARDA, Gabriel. 1980. Conjuntos urbanos histórico arquitectónicos: Valdivia, s. XVIII-XIX. Santiago de Chile: Ediciones Nueva Universidad, Pontificia Universidad Católica de Chile.

Guarda, Gabriel. 1981. Provincia de Osorno: Arquitectura en madera: 1850-1928. Santiago de Chile: Ediciones Universidad Católica de Chile.

GUARDA, Gabriel. 1995. La tradición de la madera. Santiago de Chile: Ediciones Universidad Católica de Chile.

GuTKIND, Erwin Anton. 1964. Urban development in Central Europe. International history of city development, vol. I. New York: Free Press.

Moser, Johanna. 2013. Importación selectiva y adaptación: transformación en la estructura de cubierta de las casas de colonos chilenoalemanes. En D`Alençon Castrillón, Renato y Prado Garcia, Francisco (ed.), Constructores Inmigrantes: Transferencias de Alemania a Chile 1851-1875. Santiago de Chile: Ediciones Universidad Católica de Chile.

Pérez Rosales, Vicente. 1886. Recuerdos del pasado 1814-1860. Santiago de Chile: Imprenta Gutenberg.

Peri Fagerstrom, René. 1989. Reseña de la colonización en Chile. Santiago de Chile: Editorial Andrés Bello.

PHILIPPI, Rodulfo A. 1901. Valdivia en 1852. La Revista de Chile, 73: 297-300 y 74: 329-335.

SAnchez Aguilera, Victor. 1948. El Pasado de Osorno: la gran ciudad del porvenir. Osorno: imprenta Cervantes.

Vicuña Mackenna, Benjamín. 1865. Bases del informe presentado al supremo gobierno sobre la inmigración extranjera por la comisión especial nombrada con ese objeto $i$ redactada por el secretario de ella. Santiago de Chile: imprenta Nacional.

Referencia página web:

Ref. web 1: www.memoriachilena.cl/602/w3-article-98568.html (visitado 13 sept. 2016).

Fecha final recepción artículos: 20/04/2017

Fecha aceptación:

05/07/2017

Artículo sometido a revisión por dos revisores independientes por el método doble ciego. 